\title{
Adapting the thermal-based two-source energy balance model to estimate energy fluxes in a complex tree-grass ecosystem
}

\author{
Vicente Burchard-Levine $^{1 *}$, Héctor Nieto $^{2}$, David Riaño ${ }^{1,3}$, Mirco Migliavacca ${ }^{4}$, Tarek S. El-Madany ${ }^{4}$,
} Oscar Perez-Priego ${ }^{5}$, Arnaud Carrara ${ }^{6}$ and M. Pilar Martín ${ }^{1}$

1 Environmental Remote Sensing and Spectroscopy Laboratory (SpecLab), Spanish National Research Council (CSIC), Madrid, Spain; vicentefelipe.burchard@cchs.csic.es; mpilar.martin@cchs.csic.es; david.riano@cchs.csic.es

2 Complutum Tecnologías de la Información Geográfica S.L. (COMPLUTIG), Alcalá de Henares, Spain. Email hector.nieto@complutig.com

3 Center for Spatial Technologies and Remote Sensing (CSTARS), University of California, 139 Veihmeyer Hall, One Shields Avenue, Davis, CA 95616,USA

4 Max Planck Institute for Biogeochemistry, Department Biogeochemical Integration, Hans-Knöll-Str. 10, 07745 Jena, Germany; mmiglia@bgc-jena.mpg.de; telmad@bgc-jena.mpg.de

5 Department of Biological Sciences, Macquarie University, Sydney, NSW, 2109, Australia; oscar.perez-

6 Fundación Centro de Estudios Ambientales del Mediterráneo (CEAM), Valencia 46980, Spain; arnaud@ceam.es

Correspondence to: Vicente Burchard-Levine (vicentefelipe.burchard@ @cchs.csic.es)

Abstract. The thermal-based Two-Source Energy Balance (TSEB) model has successfully simulated energy fluxes in a wide

range of landscapes. However, tree-grass ecosystems (TGE) have notably complex heterogenous vegetation mixtures and dynamic phenological characteristics presenting clear challenges to earth observation and modeling methods. Therefore, the TSEB model was adapted here to consider these significant seasonal changes. To ensure this and understand model dynamics, sensitivity analyses (SA) were conducted on both inputs (local SA) and parameters (global SA). Furthermore, a more physically based wind attenuation sub-model was applied and compared against the classical exponential wind attenuation law. The model was subsequently modified (TSEB-2S) and evaluated against eddy covariance (EC) flux measurements and lysimeters over a TGE experimental site in central Spain. TSEB-2S vastly improved modeled fluxes decreasing the mean bias and RMSD of LE from 34 and $77 \mathrm{~W} \mathrm{~m}^{-2}$ to 4 and $56 \mathrm{~W} \mathrm{~m}^{-2}$, respectively during 2015. TSEB-2S was further validated for two other EC towers and for different years (2015, 2016 and 2017) obtaining similar error statistics. The results presented here demonstrate the important role that vegetation, through its structure and phenology, has in controlling ecosystem level energy fluxes, which become important considerations for the modeling procedure. Additionally, TSEB showed to be more sensitive to correctly partitioning incoming radiation, such as characterizing vegetation clumping, compared to accurately modeling the wind profile through the canopy or the aerodynamic roughness. 
https://doi.org/10.5194/hess-2019-354

Preprint. Discussion started: 29 August 2019

(c) Author(s) 2019. CC BY 4.0 License.

Table of variables

\begin{tabular}{|c|c|c|}
\hline Variable & Description & Units \\
\hline$\alpha_{P T}$ & Priestley Taylor coefficient for potential transpiration & - \\
\hline$b$ & Soil-surface resistance (Rs) constant & 0.012 \\
\hline$c$ & Constant in soil-surface resistance $(R s)$ & $\mathrm{m} \mathrm{s}^{-1} \mathrm{~K}^{-1 / 3}$ \\
\hline$C^{\prime}$ & Constant in total boundary resistance $(R x)$ & $\mathrm{s}^{1 / 2} \mathrm{~m}^{-1}$ \\
\hline$c_{d}$ & Equivalent drag coefficient of the foliage elements & - \\
\hline$f_{c}$ & Fractional cover & - \\
\hline$f_{g}$ & Fraction of vegetation that is green & - \\
\hline$G$ & Soil heat flux & $\mathrm{W} \mathrm{m}^{-2}$ \\
\hline$h_{c}$ & Canopy height & $\mathrm{m}$ \\
\hline$H$ & Sensible heat flux & $\mathrm{W} \mathrm{m}^{-2}$ \\
\hline$H_{c}$ & Sensible heat flux from canopy source & $\mathrm{W} \mathrm{m}^{-2}$ \\
\hline$H_{s}$ & Sensible heat flux from soil source & $\mathrm{W} \mathrm{m}^{-2}$ \\
\hline$k_{b e}$ & Beam extinction coefficient & - \\
\hline$L A I$ & Leaf Area Index & $\mathrm{m}^{2} \mathrm{~m}^{-2}$ \\
\hline$L E$ & Latent heat flux & $\mathrm{W} \mathrm{m}^{-2}$ \\
\hline$L E_{c}$ & Latent heat flux from the canopy source & $\mathrm{W} \mathrm{m}^{-2}$ \\
\hline$L E_{s}$ & Latent heat flux from the soil source & $\mathrm{W} \mathrm{m}^{-2}$ \\
\hline$L E_{l y s}$ & $\begin{array}{l}\text { Latent heat flux from the understory measured by the } \\
\text { lysimeter }\end{array}$ & $\mathrm{W} \mathrm{m}^{-2}$ \\
\hline$L S T$ & Radiometric Land Surface Temperature & $\mathrm{K}$ \\
\hline$l_{w}$ & Averageleffective leaf width & $\mathrm{m}$ \\
\hline$N D V I$ & Normalized difference vegetation index & - \\
\hline$R_{A}$ & Aerodynamic resistance to heat transfer & $\mathrm{s} \mathrm{m}^{-1}$ \\
\hline$R n$ & Net radiation flux & $\mathrm{W} \mathrm{m}^{-2}$ \\
\hline$R n, c$ & Net radiation flux at canopy source & $\mathrm{W} \mathrm{m}^{-2}$ \\
\hline$R n, s$ & Net radiation flux at soil source & $\mathrm{W} \mathrm{m}^{-2}$ \\
\hline$R_{S}$ & $\begin{array}{l}\text { resistance to heat transfer in the boundary layer above soil } \\
\text { layer }\end{array}$ & $\mathrm{s} \mathrm{m}^{-1}$ \\
\hline$R_{X}$ & the bulk canopy resistance to heat transfer & $\mathrm{s} \mathrm{m}^{-1}$ \\
\hline$T_{A C}$ & Air temperature in the canopy space & $\mathrm{K}$ \\
\hline$T_{c}$ & Vegetation canopy temperature & $\mathrm{K}$ \\
\hline$T_{s}$ & Soil surface temperature & $\mathrm{K}$ \\
\hline$w_{c}$ & Canopy width to height ratio & - \\
\hline$X_{L A D}$ & $\begin{array}{l}\text { Campbell } 1990 \text { leaf inclination distribution function chi } \\
\text { parameter }\end{array}$ & - \\
\hline$z 0_{\text {soil }}$ & Bare soil aerodynamic roughness length & $\mathrm{m}$ \\
\hline
\end{tabular}


https://doi.org/10.5194/hess-2019-354

Hydrology and

Preprint. Discussion started: 29 August 2019

(c) Author(s) 2019. CC BY 4.0 License.

\section{Introduction}

Land surface models, mathematical representations of surface-atmospheric exchanges, are increasingly being used to understand fluxes of energy and mass, which drive climatic and Earth system processes (Bonan and Doney, 2018).

40 Heterogeneous vegetated surface layers add further complexities to these models, where structural and physiological characteristics must be better integrated in space and time, due to their important impact on energy budget partitioning. Horizontal and vertical complexities of vegetated components, along with temporal and phenological dynamics, present notable challenges for earth observation techniques to model and monitor ecosystem functional properties. Knowledge of these interactions is crucial to understand the response of ecosystems to climate and environmental changes, and Earth system dynamics (Krinner et al., 2005; Richardson et al., 2013).

Particularly, latent heat flux (LE), the aggregated water flux consisting of evaporation from the soil and other wet surfaces $\left(\mathrm{LE}_{\mathrm{s}}\right)$ and plant transpiration $\left(\mathrm{LE}_{\mathrm{c}}\right)$, has recently been the subject of extensive research (Stoy et al., 2019), being a key process that interlinks the water and energy budget along with carbon cycling through the processes of transpiration and photosynthesis (Jasechko et al., 2013). Surface energy balance models, which exploit radiometric land surface temperature (LST) from remote sensing as a key boundary condition, are increasingly being used to estimate LE (Colaizzi et al., 2016; Kalma et al., 2008; Kustas and Anderson, 2009). The two-source energy balance (TSEB) model (Kustas and Norman, 1999; Norman et al., 1995) is such a model that has been widely and successfully applied in a variety of landscapes (e.g. GonzalezDugo et al., 2009; Guzinski et al., 2013; Kustas et al., 2016; Nieto et al., 2019). The TSEB modeling scheme explicitly separates the temperature and energy exchange considering two distinct layers: vegetation and soil. However, certain landscapes, such as tree-grass ecosystems (TGE), add the complexity that the vegetation layer is represented by a heterogeneous mix between tree and grass species, each with substantially different physical, physiological and structural properties. This subsequently makes it difficult to parameterize the vegetated component according to specific characteristics. Additionally, the degree in which each type of vegetation (i.e. tree and grass) both influence land-surface interactions changes throughout the year, depending on their differentiated phenological stages (Luo et al., 2018). During the growing season in TGEs, trees and the grass understory, along with underlying soil, all interact to contribute to the radiative transfer and turbulent exchanges (Baldocchi et al., 2004). However, during the dry summer periods, the grass layer senescence due to meteorological conditions (i.e. water availability, air temperature, vapor pressure deficit), converting the system into (nearly) bare, rather rough, soil with scattered trees, substantially changing land-atmospheric dynamics (Perez-

65 Priego et al., 2018). To tackle these complexities, we propose here a modeling procedure that uses a composite of ecosystems over time, where the parameterization of the vegetated layer changes depending on the phenological period.

Environmental models, including hydrological and land-surface models, have developed significantly over the past years adding increasingly complex modeling procedures and parameterization. A sensitivity analysis (SA) has become 
https://doi.org/10.5194/hess-2019-354

Hydrology and

Preprint. Discussion started: 29 August 2019

(c) Author(s) 2019. CC BY 4.0 License.

70 instrumental to understand model dynamics by providing insight in how parameters affect model outputs (Song et al., 2015). Model uncertainty stems from three main sources: 1) errors associated with input data, 2) imperfection of model structure, and 3) uncertainty in model's parameters (Jin et al., 2010; Migliavacca et al., 2012). This is particularly important in overparameterizated models that are unnecessarily complex with large uncertainties in parameters, which is a well-described issue (Beven, 1989; van Griensven et al., 2006). Different SA methods exist which are often distinguished between local and global techniques. Local methods compute the main response $\left(1^{\text {st }}\right.$ order$)$ of the model with respect to changes in single parameter values while keeping other parameters constant (i.e. one-at-a-time). Global methods evaluate the whole parameter space simultaneously and, thus, compute both the main effect $\left(1^{\text {st }}\right.$ order $)$ and the interactions between parameters $\left(2^{\text {nd }}\right.$ order $)$ to obtain the total parameter contribution (total order) to variability in model output. It is now widely argued that local SA techniques are unsuitable for complex non-linear models since there are often strong and significant parameter interactions (Pianosi et al., 2017; Rosolem et al., 2012). While other studies have investigated the sensitivity of specific parameters or inputs within TSEB (e.g. Alfieri et al., 2019; Andreu et al., 2018; Gan and Gao, 2015; Li et al., 2005) or performed a SA to optimize TSEB (e.g. Diarra et al., 2017), a comprehensive SA for TSEB has not been discussed in the literature, especially for complex ecosystems, such as TGEs, where surface heterogeneity may potentially lead to increases in parameterization and complexities.

The main objective of this paper is to test whether a simple adaptation to TSEB, namely considering two distinct phenological and modeling periods throughout the year, can produce reliable estimations of energy fluxes for a spatially and temporally complex TGE. Prior to this, a SA is performed on parameters and inputs to quantify and pinpoint the different sources of uncertainties within the modeling procedure. A Sobol' global SA (Saltelli et al., 2010; Sobol', 2001) is performed on the main parameters within TSEB combined with a local SA of the two main inputs: land surface temperature (LST) and leaf area index (LAI). Two modeling structures, with a varying degree of complexity, are tested: one embedded with the classical Goudriaan (1977) wind attenuation formulation and, another using Massman et al. (2017)'s more physically-based wind attenuation scheme (section 2.2.2). The modified model results are evaluated against three independent eddy covariance (EC) systems, including partitioned LE (Perez-Priego et al., 2018), and lysimeter measurements located within

95 the Majadas experimental site (Perez-Priego et al., 2017). The primary objective is to evaluate the simulated bulk fluxes (i.e. LE) for the whole vegetation-soil system with a secondary goal to investigate the suitability of the LE partitioning, between $\mathrm{LE}_{\mathrm{s}}$ and $\mathrm{LE}_{\mathrm{c}}$, estimated by TSEB.

\section{Materials and Methods}

\subsection{Study Site}

100 The TSEB model was applied to estimate energy fluxes in a TGE located in Majadas de Tiétar $\left(39^{\circ} 56^{\prime} 24.68^{\prime \prime} \mathrm{N}\right.$, $5^{\circ} 46^{\prime} 28.70^{\prime \prime} \mathrm{W}$ ) in central Spain (Casals et al., 2009; El-Madany et al., 2018). These types of ecosystems are prevalent, 
covering nearly $15 \%$ of the total Earth surface (Friedl et al., 2010), and are notably valuable in both an economic (i.e. livestock grazing) and ecological (i.e. biodiversity and carbon sequestration) sense. Majadas de Tiétar is a well-established experimental site composed of scattered oak trees, mostly Holm Oak (Quercus ilex. L.), above an herbaceous vegetation understory or grass layer. Holm Oak trees cover roughly $20 \%$ of the total land surface and stand at a mean height of $8 \mathrm{~m}$ (ElMadany et al., 2018). The site is a managed semi-natural agroforested area (Spanish 'dehesa') with low-intensity grazing from livestock $\left(<0.3\right.$ cows ha $\left.{ }^{-1}\right)$. It lies within a continental Mediterranean climate region with mean annual temperature of $16.7^{\circ} \mathrm{C}$ and annual precipitation of about $650 \mathrm{~mm}$ (with significant inter-annual variability) (Luo et al., 2018). The area is characterized by very hot and dry summer periods (June to September), with grass rapidly drying and senescing during these periods. The average grass LAI ranges roughly between $0.3-3.0 \mathrm{~m}^{2} \mathrm{~m}^{-2}$ throughout the year and can present high variability in spring period (between $0.5-2.5 \mathrm{~m}^{2} \mathrm{~m}^{-2}$ ) due to its spatial heterogeneity (El-Madany et al., 2018; Migliavacca et al., 2017). Trees have developed extensive root systems enabling them to survive during long drought periods and, thus, have less temporal variability (mean tree LAI ranging between $1.39-1.75 \mathrm{~m}^{2} \mathrm{~m}^{-2}$ ). As such, the distinct survival strategies between grass and tree species allow for coexistence. Three EC towers are present within this experimental site. They are located relatively close to each other $(<650 \mathrm{~m}$, Fig. 1$)$ with similar properties within their footprint, but belong to a large scale manipulation experiment, where nitrogen was added to the northern tower (NT), nitrogen and phosphorus were added to the southern tower (NPT) and the central tower kept as a control (CT) (El-Madany et al., 2018.; Luo et al., 2018).

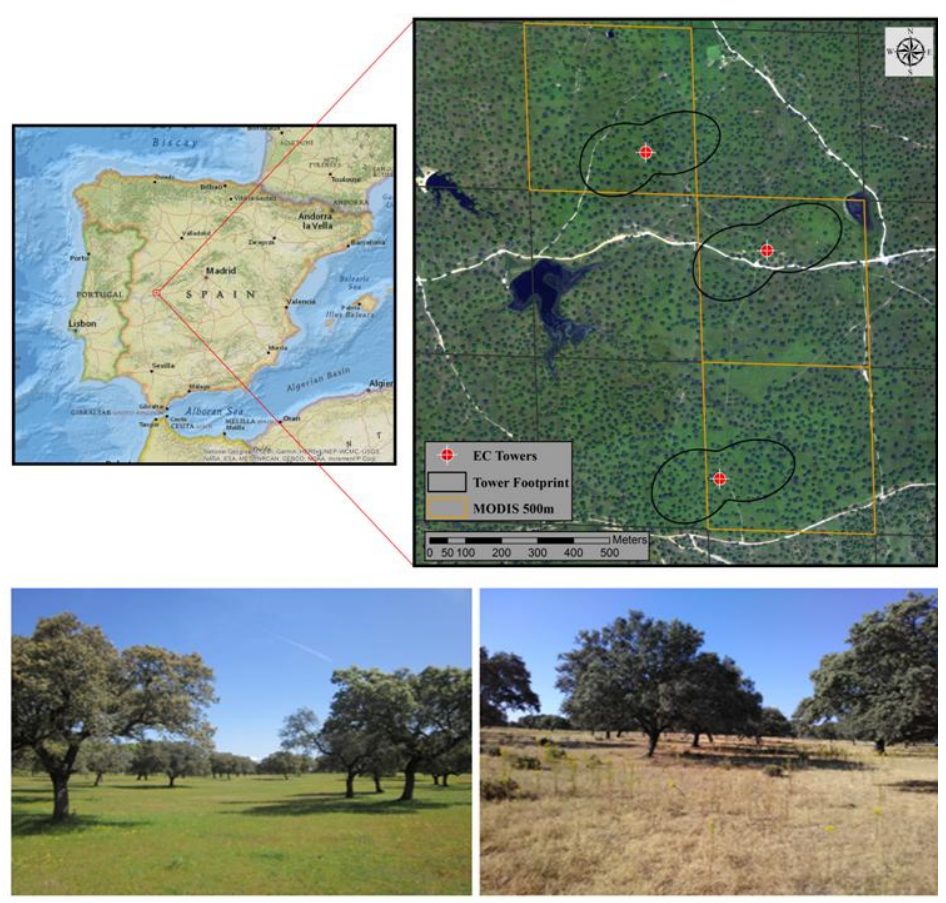

Figure 1. Majadas experimental site and location of the three EC towers indicated by red points, with respective footprints (60\% iso-lines for the period of March 2014 until January 2017 and estimated according to Kljun et al. (2015)) in early spring (lower left) and summer (lower right). Selected MODIS 500m pixels for LAI estimations (section 2.3.2) are highlighted in orange. The upper left panel reference map was created using ArcMap 10.3 online basemaps (ESRI. 'National Geographic', http://www.arcgis.com/home/item.html?id=30e5fe3149c34df1ba922e6f5bbf808f, 13 December 2011) 


\subsection{TSEB Model Overview}

125 The TSEB model was first proposed in Norman et al. (1995), with important adjustments described in Kustas and Norman (1999). Its main inputs are LST, derived from thermal infrared (TIR) radiation, vegetation structural properties (e.g LAI, canopy height) and meteorological forcing. The principle source of uncertainty within TSEB lies in the estimation of the sensible heat flux $(\mathrm{H})$, which is calculated through the heat transport equation (eq. 1).

$$
H=\frac{\rho C_{p}\left(T_{o}-T_{A}\right)}{R_{H}}
$$

where $\mathrm{H}$ is sensible heat flux $\left(\mathrm{W} \mathrm{m} \mathrm{m}^{-2}\right) ; \rho C_{p}$ is the volumetric heat capacity of air $\left(\mathrm{J} \mathrm{m}^{-3} \mathrm{~K}^{-1}\right) ; T_{o}$ is the aerodynamic temperature of the surface $(\mathrm{K}) ; T_{A}$ is the air temperature at a reference/measurement height $(\mathrm{K})$; and $R_{H}$ is the aerodynamic resistance to heat transport $\left(\mathrm{s} \mathrm{m}^{-1}\right)$. The heat transport equation is satisfied when using aerodynamic surface temperature (i.e. surface temperature at the canopy source-sink height), however, LST obtained from TIR remote sensing (i.e. skin radiometric surface temperature) can differ up to several degrees compared to the aerodynamic surface temperature (Norman et al., 1995), and their relationship is not well established (i.e. Colaizzi et al., 2004). TSEB, thus, tackles this by assuming that the total blackbody thermal radiance that is emitted by the bulk surface is weighted by the fraction of vegetation observed by the sensor and the emission of both soil and vegetation surfaces, as expressed in eq. 2 taken from Norman et al. (1995):

$$
\operatorname{LST}(\theta)=\left[f(\theta) T_{c}^{4}+(1-f(\theta)) T_{s}^{4}\right]^{1 / 4}
$$

where $f(\theta)$ is the fraction of vegetation observed by the TIR sensor at an angle $\theta$ and is mainly a function of LAI; $T_{c}$ is the vegetation canopy temperature (K); and $T_{S}$ is the soil surface temperature $(\mathrm{K})$. Using this scheme, TSEB avoids the use of an empirical method to link radiometric and aerodynamic surface temperature, such as the use of excess resistance in SEBS (Su, 2002) or the use of hot and cold end member pixels in METRIC (Allen et al., 2007) and SEBAL (Bastiaanssen et al., 1998).

145 Using this two-layer approach, the energy balance is formulated in TSEB for each of the layers separately as follows:

$$
\begin{gathered}
R_{N, c}=L E_{c}+H_{c} \\
R_{N, S}=L E_{S}+H_{s}+G
\end{gathered}
$$

where $R_{N}$ is the net radiation ( $\mathrm{W} \mathrm{m}^{-2}$ ); is latent heat flux $\left(\mathrm{W} \mathrm{m}^{-2}\right) ; G$ is the soil heat flux ( $\mathrm{W} \mathrm{m}^{-2}$ ); and subscript $s$ and $c$ refer to soil and vegetation canopy layers, respectively. Note that storage terms as well as the energy used for photosynthesis are neglected here. Radiative transfer and absorption through the canopy $\left(R_{N, c}\right.$ and $\left.R_{N, S}\right)$ is simulated through an exponential radiation extinction function as described in chapter 15 of Campbell and Norman (1998), considering spectral differences in 
https://doi.org/10.5194/hess-2019-354

Preprint. Discussion started: 29 August 2019

(c) Author(s) 2019. CC BY 4.0 License.

shortwave and longwave radiation and direct and diffuse radiation as incorporated in Kustas and Norman (1999). H is derived using an in 'series' resistance network (Norman et al., 1995) (Fig. 2), and applying eq. 4 to 6, which allows for heat turbulent interchange between the canopy and soil layers:

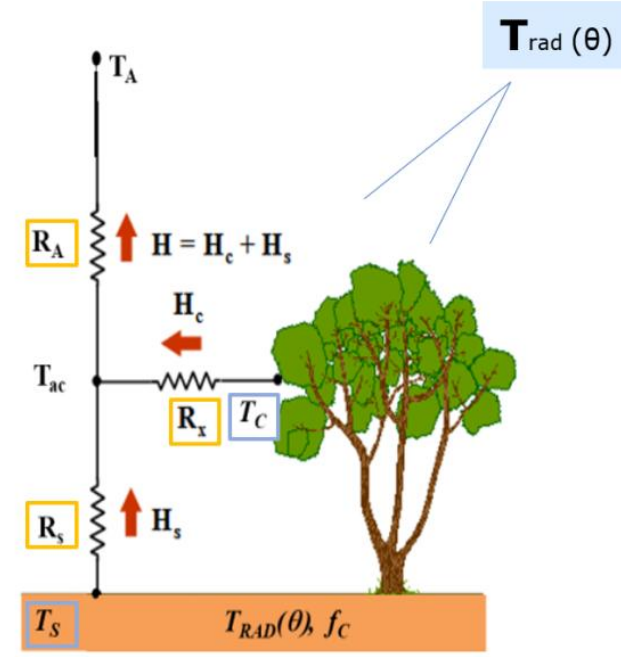

Figure 2.TSEB Sensible Heat model scheme (adapted from Kustas and Anderson, 2009)

$$
H_{s}=\frac{\rho C_{p}\left(T_{s}-T_{A C}\right)}{R_{S}}
$$

$$
\begin{gathered}
H_{c}=\frac{\rho C_{p}\left(T_{c}-T_{A C}\right)}{R_{X}} \\
H=H_{S}+H_{c}=\frac{\rho C_{p}\left(T_{A C}-T_{A}\right)}{R_{A}}
\end{gathered}
$$

where $\mathrm{T}_{\mathrm{AC}}$ is the air temperature in the canopy space $(\mathrm{K})$ and is equivalent to the aerodynamic temperature $\left(\mathrm{T}_{0}\right) ; R_{S}$ is the resistance to heat transfer in the boundary layer above soil layer $\left(\mathrm{s} \mathrm{m}^{-1}\right) ; R_{X}$ is the bulk canopy resistance to heat transfer ( $\mathrm{s}$ $\left.\mathrm{m}^{-1}\right) ; R_{A}$ is the aerodynamic resistance to heat transfer based on the Monin-Obukhov similarity theory. Refer to appendix A of Norman et al. (1995) for details on the series resistance scheme.

Since eq. 2 has two unknowns ( $\mathrm{T}_{\mathrm{c}}$ and $\mathrm{T}_{\mathrm{s}}$ ), the canopy layer is assumed, as a first estimate, to be initially transpiring at a potential rate $\left(L E_{c i}\right)$ using, in this case, the Priestly-Taylor formulation: 


$$
L E_{c i}=\alpha_{P T} f_{g}\left(\frac{\Delta}{\Delta+\gamma}\right) R_{N, c}
$$

where $\boldsymbol{L} \boldsymbol{E}_{\boldsymbol{c} \boldsymbol{i}}$ is the initial canopy transpiration estimate $\left(\mathrm{W} \mathrm{m}^{-2}\right) ; \alpha_{P T}$ is the Priestley-Taylor coefficient (default is 1.26), defined in this case only for the canopy component (Kustas and Anderson, 2009) (-); $f_{g}$ is the fraction of vegetation that is green and hence actively transpiring (-); $\Delta$ is the slope of the saturation vapor pressure curve at air temperature $T_{A}\left(\mathrm{kPa} \mathrm{K}^{-1}\right)$; and $\gamma$ is the psychrometric constant $\left(\mathrm{kPa} \mathrm{K}^{-1}\right)$. This initial assumption, where the canopy is transpiring without water stress, permits to solve all the systems of equations presented above (eq. 2 to 7). However, if the vegetation is stressed, the Priestley-Taylor formulation will overestimate the transpiration of the canopy, which, in order to conserve the total surface temperature and energy balance in eq. 2 to 3, will result in unrealistic soil condensation (i.e. negative fluxes). As it is assumed that condensation does not occur during daytime convective conditions, an iteration procedure is applied that reduces $\alpha_{P T}$ until realistic soil fluxes area achieved (i.e. $L E_{s} \geq 0$ ). A more complete discussion on conditions that reduces $\alpha_{P T}$ is given in Anderson et al. (2005) and Li et al. (2005). For more implementation details, the reader is referred to the source code (https://github.com/hectornieto/pyTSEB) and Norman et al. (1995).

TSEB was originally developed for homogeneous cover types, however, adaptations to the model framework have been implemented to better depict partial canopy cover. These include the addition of vegetation clumping index for radiation interception and transmission (Kustas and Norman, 1999) (section 2.2.1) and incorporating a more physically based withincanopy wind attenuation scheme, incorporating the effect of canopy structure, as proposed by Massman et al. (2017) (section 2.2.2). However, as Andreu et al. (2018) demonstrated, further adaptations to model structure and parameters may be necessary to simulate fluxes over complex land surfaces such as TGEs.

\subsubsection{Radiation transmission in sparse vegetation}

The structure and distribution of foliage in the vegetative layer has a significant impact on the dynamics of radiation interception and transmission through the canopy (Anderson et al., 2005; García et al., 2015; Kustas and Norman, 1999). This in turn has a very important implication for radiometric temperature partitioning between the soil and vegetation components and their resulting contribution to heat fluxes (Anderson et al., 2005). The original TSEB radiative transfer equations assume a randomly distributed homogenous (non-clumped) canopy (Norman et al., 1995). However, sparse vegetation is generally clumped and tends to intercept less radiation for the same LAI compared to vegetation randomly dispersed over the surface (Campbell and Norman, 1998; Kustas and Norman, 1999). As such, the clumping index $(\Omega)$ quantifies the spatial distribution of foliage to account for non-randomness in vegetated structures. LAI is multiplied by the clumping factor to obtain effective LAI ( $\Omega$ LAI). As incorporated in Kustas and Norman (1999), TSEB estimates $\Omega$ as a function of the difference between the canopy gap fraction compared to a homogenous case using eq. 8 (section 2 in Kustas 
https://doi.org/10.5194/hess-2019-354

Preprint. Discussion started: 29 August 2019

(c) Author(s) 2019. CC BY 4.0 License.

and Norman, 1999) and estimating the beam extinction coefficient assuming an ellipsoidal leaf angle distribution with eq. 9 (section 15.2 in Campbell and Norman, 1998).

$$
\begin{aligned}
& \Omega(0)=\frac{-\ln \left(f_{c} \exp \left(-k_{b e} F\right)+\left(1-f_{c}\right)\right)}{k_{b e} \mathrm{~F}} \\
& k_{b e}=\frac{\sqrt{X_{L A D}{ }^{2}+\tan ^{2}(0)}}{X_{L A D}+1.774\left(X_{L A D}+1.182\right)^{-0.733}}
\end{aligned}
$$

Where $\boldsymbol{\Omega}(\mathbf{0})$ is the is the clumping index when the vegetation canopy is viewed at nadir (-); $k_{b e}$ is the beam extinction coefficient (-) based on a ellipsoidal leaf angle distribution (LAD) (Campbell and Norman, 1998); $f_{c}$ is the vegetation fractional cover (-); $\mathrm{F}$ is the local LAI $\left(\mathrm{LAI} / f_{c}\right)$; and $X_{L A D}$ is the leaf inclination distribution function chi parameter (-) (Campbell and Norman, 1998). $\Omega$ is also dependent on the solar zenith angle $\left(\theta_{s}\right)$ and is estimated using eq. 10 as described in section 15.13 of Campbell and Norman (1998).

$$
\Omega\left(\theta_{S}\right)=\frac{\Omega(0)}{\Omega(0)+[1-\Omega(0)] \exp \left[-2.2\left(\theta_{S}\right)^{\mathrm{p}}\right]}
$$

210 where $p=3.8-0.46\left(\frac{1}{w_{c}}\right)$; and $w_{c}$ is the vegetation's width to height ratio (-).

\subsubsection{Aerodynamic resistances and within-canopy wind speed profile}

The semi-empirical derivations of $R_{S}$ and $R_{X}$, as introduced in Norman et al. (1995) and Kustas and Norman (1999), are dependent on wind speeds below and within the vegetative canopy, respectively (eq. 11-12).

$$
\begin{gathered}
R_{S}=\frac{1}{c\left(T_{s}-T_{c}\right)^{1 / 3}+b u_{s}} \\
R_{X}=\frac{C^{\prime} \sqrt{l_{w / u_{d_{o}+z_{0}}}}}{L A I}
\end{gathered}
$$

where $u_{s}$ is the wind speed just above the surface where the impact of soil roughness is minimal (i.e. $\left.z 0_{\text {soil }}\right)\left(\mathrm{ms}^{-1}\right) ; u_{d_{o}+z_{o}}$ is the wind speed within the canopy-air interspace at the height of momentum source/sink $\left(\mathrm{ms}^{-1}\right) ; l_{w}$ is the effective leaf width size (m); and c $\left(\mathrm{m} \mathrm{s}^{-1} \mathrm{~K}^{-1 / 3}\right), \mathrm{b}(-)$ and $\mathrm{C}^{\prime}\left(\mathrm{s}^{1 / 2} \mathrm{~m}^{-1}\right)$ are coefficients taken from Kustas and Norman (1999) and Norman et al. 
https://doi.org/10.5194/hess-2019-354

Hydrology and

Preprint. Discussion started: 29 August 2019

(c) Author(s) 2019. CC BY 4.0 License.

(1995), based on the works of Sauer and Norman (1995), Kondo and Ishida (1997) and McNaughton and Van Den Hurk

(1995) (default values are $0.0025,0.012$ and 90 respectively). TSEB determines the two key roughness parameters, the zeroplane displacement height $\left(\mathrm{d}_{0}\right)$ and the aerodynamic roughness length for momentum transfer $\left(z_{0 m}\right)$, from the vegetation structure. When considering the grass canopy layer, the traditional fixed ratio to canopy height method is used to estimate $\mathrm{d}_{0}$ and $z_{0 m}$ (Campbell and Norman, 1998). In the case of the tree canopy layer, a different approach is used, which additionally considers the canopy shape and density's effect on the roughness parameters. TSEB follows the procedure described in Schaudt and Dickinson (2000), which stems from the work of Raupach (1994) and Lindroth (1993), and is generally viewed as more suitable for tall wooded vegetation. These methods do not apply corrections associated to the roughness sub-layer (e.g. Weligepolage et al., 2012). However, Alfieri et al (2019) found that the TSEB modeled fluxes were largely insensitive to differences in estimated $\mathrm{d}_{0}$ and $z_{0 m}$ obtained from various methods.

$u_{s}$ and $u_{d_{o}+z_{0 m}}$ in eq. 11 and 12 are both derived from an observed wind speed above the canopy that is extrapolated through and below the canopy using a wind profile modeling scheme. The classical modeling approach within TSEB is based on the exponential wind attenuation law (Goudriaan, 1977). However, this approach was largely designed for homogeneous and dense vegetation layers and may not be suitable for sparsely, clumped or non-uniformly structured vegetation that will likely impact the wind attenuation flowing through its porous medium (Alfieri et al., 2019). Recently, Massman et al. (2017) proposed a more physically-based wind attenuation scheme to take into account the effect of canopy shape and structure on wind speed, allowing for a smoother transition between partial to full canopy cover. Their main additional input is the canopy foliage vertical distribution, based on the Plant (leaf + stem) Area Index and the relative canopy shape. A logarithmic profile is dominant near the ground surface and lower part of canopy, while a hyperbolic cosine profile dominates higher parts of the canopy, where its foliage would most affect wind speed (Nieto et al., 2019). A drag coefficient ( $c_{d}$ ) of foliage elements also characterizes the turbid medium canopy, which is usually considered to be 0.2 (Goudriaan, 1977; Massman et al., 2017). Both the Massman et al (2017) and Goudriaan (1977) wind profile schemes are incorporated within TSEB in this study to evaluate on their respective influence on simulated fluxes.

\subsection{Data}

\subsubsection{Eddy covariance and biometerological measurements}

The three EC towers (CT - FLUXNET identifier ES-LMa, NT - FLUXNET ID ES-LM1, and NPT - FLUXNET ID ES-

245 LM2), simultaneously operating within the Majadas study site, provided all necessary inputs to run TSEB (Table 1), except for continuous vegetation LAI measurements/estimates (section 2.5.2). $\mathrm{H}$ and LE estimations from the EC system served to benchmark model performance. Details on the data processing are found in El-Madany et al. (2018). Data were obtained between the period of 2015-01-01 and 2017-12-31. Since TSEB closes the energy balance by definition, energy balance closure of the EC flux measurements was ensured by allocating the residuals to the observed LE, assuming that errors in LE 
https://doi.org/10.5194/hess-2019-354

250 are larger than $\mathrm{H}$ due to issues related to the instrumentation (Foken et al., 2011), as done in, among other studies, Guzinski et al. (2014) and Kustas et al. (2012). Measurements from 2015 of the CT tower were selected as the 'main' simulation period. This period was used to perform the SA (section 2.4.2) and to adapt the model for seasonality (section 2.4.4). Other towers (NT and NPT) and years (2016 and 2017) provided independent evaluations of model performance (section 2.4.5).

While TSEB is embedded with different methods to estimate ground heat flux (G) (Norman et al., 1995; Santanello and Friedl, 2003), this study directly forced G measurements as a model input to limit uncertainty and noise in turbulent flux estimations associated with errors in G. The weighted average of 8 soil heat flux plates represented $\mathrm{G}$ at the ecosystem level. They were located both in open grass and below tree canopy and weighted to consider shadow effects throughout the day. Note that corrections related to heat storage above the soil heat flux plates were not applied and, as such, G is likely slightly underestimated. The radiometric LST was estimated using longwave radiation measurements from the 4-component radiometer CNR4 (Kipp \& Zonen, Delft, Netherlands) as follows:

$$
\begin{gathered}
L S T=\left(\frac{L_{\text {out }}-\left(1-\varepsilon_{\text {surf }}\right) L_{\text {in }}}{\sigma \varepsilon_{\text {surf }}}\right)^{1 / 4} \\
\varepsilon_{\text {surf }}=f_{c} 0.99+\left(1-f_{c}\right) 0.94
\end{gathered}
$$

where $L_{\text {out }}$ and $L_{\text {in }}$ are upwelling and downwelling longwave radiance; $\sigma$ is the Stephan-Boltzman constant; $\varepsilon_{\text {surf }}$ is the surface emissivity; and $f_{c}$ is the vegetation fractional cover. The values of 0.99 and 0.94 in eq. 13 correspond to the emissivity for vegetation and bare soil respectively (Sobrino et al., 2005).

\begin{tabular}{|c|c|c|}
\hline Variable & Description & Instruments \\
\hline LST & $\begin{array}{l}\text { Land surface temperature }(\mathrm{K}) \text { estimated from longwave } \\
\text { radiation }\end{array}$ & $\begin{array}{l}\text { 4-component radiometer (CNR4, } \\
\text { Kipp \& Zonen, Delft, Netherlands) }\end{array}$ \\
\hline $\mathrm{T}_{\mathrm{a}}$ & Air temperature $(\mathrm{K})$ measured at $15 \mathrm{~m}$ & Hygro.Thermo transmitter \\
\hline RH & Relative humidity (\%) measured at $15 \mathrm{~m}$ & Hygro.Thermo transmitter \\
\hline $\mathrm{u}$ & Wind speed $(\mathrm{m} / \mathrm{s})$ measured at $15 \mathrm{~m}$ & $\begin{array}{l}\text { Sonic anemometer (Gill R3-50, } \\
\text { Lymington UK) }\end{array}$ \\
\hline $\mathrm{P}$ & Atmospheric pressure (mb) & Barometric pressure sensor \\
\hline $\mathrm{S}_{\mathrm{dn}}$ & Incoming shortwave irradiance $\left(\mathrm{W} \mathrm{m}^{-2}\right)$ & $\begin{array}{l}\text { 4-component radiometer (CNR4, } \\
\text { Kipp \& Zonen, Delft, Netherlands) }\end{array}$ \\
\hline $\mathrm{L}_{\text {in }}$ & Incoming longwave irradiance $\left(\mathrm{W} \mathrm{m}^{-2}\right)$ & $\begin{array}{l}\text { 4-component radiometer (CNR4, } \\
\text { Kipp \& Zonen, Delft, Netherlands }\end{array}$ \\
\hline $\mathrm{L}_{\text {out }}$ & Outgoing longwave irradiance $\left(\mathrm{W} \mathrm{m}^{-2}\right)$ & $\begin{array}{l}\text { 4-component radiometer (CNR4, } \\
\text { Kipp \& Zonen, Delft, Netherlands }\end{array}$ \\
\hline G & Soil heat flux $\left(\mathrm{W} \mathrm{m}^{-2}\right)$ & Soil heat flux plates \\
\hline $\mathrm{H}$ & Sensible heat flux $\left(\mathrm{W} \mathrm{m}^{-2}\right)$ & $\begin{array}{l}\text { 3D sonic anemometer (Gill R3-50, } \\
\text { Lymington UK } \\
\text { IRGA (Li-7200. Licor Lincoln }\end{array}$ \\
\hline LE & Latent heat flux $\left(\mathrm{W} \mathrm{m}^{-2}\right)$ & $\begin{array}{l}\text { Nebraska, USA) and 3D sonic } \\
\text { anemometer Gill R3-50, } \\
\text { Lymington UK }\end{array}$ \\
\hline
\end{tabular}

Table 1. Meteorological and flux measurements from the EC towers used to simulate and evaluate output from TSEB 
https://doi.org/10.5194/hess-2019-354

Hydrology and

Preprint. Discussion started: 29 August 2019

(c) Author(s) 2019. CC BY 4.0 License.

\subsubsection{Vegetation biophysical measurements}

Time series of reflectance factors from the MODIS/Terra and Aqua Nadir BRDF-adjusted Reflectance Daily L3 500m v006 (MCD43A4) product were acquired for pixels centered in each of the three towers (Fig. 1). The 500m by 500m pixel size was deemed adequate to characterize the tower footprint (Pacheco-Labrador et al., 2017). The normalized difference vegetation index (NDVI) was derived using band 1 (red: 620nm-670nm) and band 2 (NIR: $841 \mathrm{~nm}-876 \mathrm{~nm}$ ) as follows:

$$
N D V I=\frac{\operatorname{Band} 2(N I R)-\operatorname{Band} 1(R E D)}{\operatorname{Band} 2(N I R)+\operatorname{Band} 1(R E D)}
$$

An empirical relationship between NDVI and in-situ destructive grass LAI measurements was developed specifically for the Majadas experimental site (Appendix A, Fig.A1) using in-situ grass LAI measurements. These In situ grass LAI measurements were acquired at eleven plots $(25 \mathrm{mx} 25 \mathrm{~m})$ randomly placed around the CT (Mendiguren et al., 2015). Destructive samples were collected in two $25 \mathrm{~cm} \times 25 \mathrm{~cm}$ quadrants within each plot and LAI was derived using gravitational methods, where green and non-green elements were separated to compute both total and green LAI (as well as $f_{g}$ ). In order to obtain the ecosystem LAI adjusted for the tree canopy effect within the tower footprint, ground tree LAI measurements were incorporated to achieve a weighted average of total LAI (20\% tree and $80 \%$ grass). The average tree LAI acquired using the LAI-2200 plant canopy analyzer (LAI-2200) (LICOR Bioscience USA, 2011) during five field campaigns at different seasonal periods between 2017-2018 was used as a reference year. Tree LAI ranges between 1.39 and 1.75 and has low inter-annual variability (Luo et al., 2018). Similarly, $f_{g}$ time series were obtained through in-situ destructive measurements from 18 field campaigns during the simulation periods (2015-2017) (appendix A, Fig.A2). A simple linear interpolation between sampling dates was performed to obtain a continuous daily time series.

\subsection{Model Simulations and Evaluation}

Prior to conducting the simulations with TSEB, both a global and local SA was performed on the main parameters and inputs, respectively. Both SAs were conducted using the default TSEB model (section 2.4.1). In addition, two end member simulations, where either a pure grassland or broadleaf forest was assumed for the entire year, were performed to better understand the effect of the vegetation canopy on simulated fluxes for extreme cases (2.4.3). The model is then adapted considering two distinct seasonal periods, each having a dominating vegetation layer (section 2.4.4). Parameters related to vegetation structure are adapted for each period in order to characterize the assumed prominent vegetation (i.e. either as tree or grass), as well as taking into account the results from the SA. All simulations are evaluated for daytime fluxes (i.e. when $\mathrm{S}_{\mathrm{dn}}>25 \mathrm{Wm}^{-2}$ ) since TSEB is designed to model fluxes for daytime conditions with remote sensing data. 


\subsubsection{Default TSEB model configuration}

In this configuration, the single vegetated layer was parameterized as a mix between tree and grass, where the vegetation cover was dominated by grass $\left(f_{c}=0.8\right)$ but the turbulent resistances were assumed to be largely affected by the sparse tree layer (El-Madany et al., 2018). As such, parameters related to vegetation resistance and roughness were configured using tree characteristics (e.g. $h_{c}=8 \mathrm{~m}$, see section 2.2.2). Table 3 summarizes the parameter values for this default model. Two model structures with different wind attenuation schemes were tested: one embedded with Goudriaan (1977) and the other with Massman et al. (2017) (hereafter referred to as $\mathrm{TSEB}_{\mathrm{G}}-\mathrm{DF}$ and $\mathrm{TSEB}_{\mathrm{M}}-\mathrm{DF}$, respectively). The model simulations were performed at the sub-hourly (30-mins) time step for 2015 over the CT EC footprint and benchmarked against EC derived turbulent fluxes.

\subsubsection{Sensitivity Analysis}

\section{Sobol' Global Parameter Sensitivity Analysis}

Variance-based SA methods are now more prominently used (Rosolem et al., 2012). They decompose the total variance between simulated and observed data into various parts determining the contribution of the different parameters and their combined interactions on total output variance. Multiple model simulations are required with different parameter sets to quantify the model output variance in regard to the variation in the parameter space.

Among them, the Sobol' SA method is widely preferred as it is able to compute the $1^{\text {st }}, 2^{\text {nd }}$ and total order sensitivity indices. The main disadvantage of the Sobol' method is the high computational cost, where many simulations are required to obtain robust results within a sufficient confidence level .To apply this methodology, a selection of model parameters and their respective bounds are configured. Based on this, parameters sets for $\mathrm{n}$ simulations are generated using the Sobol sequence (Saltelli et al., 2010; Sobol', 2001), a quasi-random method with quasi-Monte-Carlo integration, which typically samples bounded space more uniformly than completely random sequences (Zhang et al., 2015).

$$
y=f(\theta)=f\left(\theta_{1}, \theta_{2}, \theta_{3} \ldots, \theta_{n}\right)
$$

where $y$ is an indicator of the model performance and $\left\{\theta_{1}, \theta_{2}, \theta_{3} \ldots, \theta_{n}\right\}$ is the model parameter set which controls the model behavior and, thus, its performance, $y$. The Sobol' approach decomposes the variance observed in $y$ through the variance in all $\theta$ factors by separating parameters into terms of increasing dimensionality, with each successive dimension representing greater interaction of parameters, represented as:

$$
\operatorname{Var}(y)=\sum_{i} V_{i}+\sum_{i} \sum_{i<j} V_{i j}+\cdots+V_{1,2,3 \ldots, n}
$$


https://doi.org/10.5194/hess-2019-354

Preprint. Discussion started: 29 August 2019

(c) Author(s) 2019. CC BY 4.0 License.

where $\operatorname{Var}(y)$ is the total output variance; $V_{i}$ is the portion of variance contributed by parameter $\theta_{1}$ (also known as the first order variance or main effect); and $V_{i j}$ is the portion of variance attributed through the interaction between $\theta_{i}$ and $\theta_{j}$ and so on. As such, the first-order sensitivity $\left(\mathrm{S}_{\mathrm{i}}\right)$, second-order sensitivity $\left(\mathrm{S}_{\mathrm{ij}}\right)$ and total order sensitivity $\left(\mathrm{S}_{\mathrm{Ti}}\right)$ indices are calculated as:

$$
S_{i}=\frac{V_{i}}{\operatorname{Var}(y)}
$$

$$
\begin{gathered}
S_{i j}=\frac{V_{i j}}{\operatorname{Var}(y)} \\
S_{T i}=1-\frac{\mathrm{V}_{\sim \mathrm{i}}}{\operatorname{Var}(\mathrm{y})}
\end{gathered}
$$

where $V_{i}$ is the average variance depicted when all parameters except for $\theta_{i}$ vary (i.e. $\theta_{i}$ is kept fixed); $S_{T i}$ represents the contribution of both the direct ( $1^{\text {st }}$ order) and indirect (sum of $2^{\text {nd }}$ order) effects of $\theta_{i}$ on the total variance, $\operatorname{Var}(y)$.

330 Model variance was calculated based on H since LE is computed through the residual of the energy balance in TSEB, where errors in $\mathrm{H}$ are transposed into LE. Root-Mean-Square Deviation (RMSD) was used as the objective function to quantify model output variance for the entire simulation year, where tower-based EC H provided the observed time series.

$$
R M S D=\sqrt{\frac{\sum\left(H_{T S E B<30 \min >}-H_{E C<30 \min >}\right)^{2}}{N}}
$$

where $H_{T S E B<30 \min >}$ is modeled $\mathrm{H}$ at a 30 minutes time step; $H_{E C<30 \mathrm{~min}}>$ is the observed $\mathrm{EC} \mathrm{H}$; and $\mathrm{N}$ is the total number of observations used. The SA was undertaken with both $\mathrm{TSEB}_{\mathrm{M}}$-DF (considering 14 parameters with 56,000 simulations) and $\mathrm{TSEB}_{\mathrm{G}}$-DF (considering 11 parameters with 45,500 simulations). Selected parameters with upper and lower bounds were defined as shown in Table 2. The Python package SALib (Sensitivity Analysis Library in Python) (Herman and Usher, 2017) was integrated with the Python implementation of TSEB (pyTSEB, https://github.com/hectornieto/pyTSEB) to perform these analyses. 
https://doi.org/10.5194/hess-2019-354

Preprint. Discussion started: 29 August 2019

(c) Author(s) 2019. CC BY 4.0 License.

Table 2. Selected parameters and bounds for the TSEB global SA

\begin{tabular}{|c|c|c|c|c|}
\hline Parameter & Description & $\begin{array}{l}\text { Lower } \\
\text { bound }\end{array}$ & $\begin{array}{l}\text { Upper } \\
\text { bound }\end{array}$ & Reference \\
\hline$\alpha_{P T}$ & $\begin{array}{l}\text { Priestley Taylor coefficient for canopy } \\
\text { potential transpiration (-) }\end{array}$ & 1.26 & 2 & (Kustas and Norman, 1999) \\
\hline$f_{g}$ & Fraction of vegetation that is green (-) & 0.01 & 1 & \\
\hline$f_{c}$ & Fractional cover (-) & 0.1 & 1 & \\
\hline$w_{c}$ & Canopy width to height ratio (-) & 0.5 & 3 & \\
\hline$X_{L A D}$ & $\begin{array}{l}\text { Campbell } 1990 \text { leaf inclination } \\
\text { distribution function chi parameter (-) }\end{array}$ & 0.5 & 3 & $\begin{array}{c}\text { (Campbell and Norman, } \\
\text { 1998) }\end{array}$ \\
\hline$h_{c}$ & Canopy height $(m)$ & 0.1 & 20 & \\
\hline$z 0_{\text {soil }}$ & $\begin{array}{l}\text { Bare soil aerodynamic roughness length } \\
(\mathrm{m})\end{array}$ & 0.005 & 0.2 & (Norman et al., 1995) \\
\hline$l_{w}$ & Averageleffective leaf width $(\mathrm{m})$ & 0.005 & 0.1 & \\
\hline$b$ & Soil-surface resistance (Rs) constant (-) & 0.012 & 0.087 & (Sauer and Norman, 1995) \\
\hline$C$ & $\begin{array}{l}\text { Soil-surface resistance }(R s) \text { constant } \\
\left(\mathrm{m} \mathrm{s}^{-1} \mathrm{~K}^{-1 / 3}\right)\end{array}$ & 0.0011 & 0.0038 & (Kondo and Ishida, 1997a) \\
\hline $\mathrm{C}^{6}$ & $\begin{array}{l}\text { Constant in total boundary resistance } \\
(R x)\left(\mathrm{s}^{1 / 2} \mathrm{~m}^{-1}\right)\end{array}$ & 50 & 150 & $\begin{array}{c}\text { (McNaughton and Van Den } \\
\text { Hurk, 1995) }\end{array}$ \\
\hline$c_{d}$ & $\begin{array}{l}\text { Equivalent drag coefficient of the } \\
\text { individual foliage elements (-) }\end{array}$ & 0.1 & 0.3 & \\
\hline$X i_{\text {soil }}$ & Ground surface roughness length (m) & 0.0001 & 0.0025 & (Massman et al., 2017) \\
\hline$h_{\max }$ & $\begin{array}{l}\text { Relative position between } \\
h_{c} \text { and base of canopy where the } \\
\text { maximum foliage density occurs (-) }\end{array}$ & 0.05 & 0.95 & \\
\hline
\end{tabular}

\section{Input Local Sensitivity Analysis}

345 Errors associated to input data are another important source to the total output uncertainty. Since input data is fluctuating at every time step, a different method is needed compared to the method used for the less time-varying parameters described above Random white noise, mimicking potential errors, over a uniform distribution of $+-3 \mathrm{~K}$ and $+-0.35 \mathrm{~m}^{2} \mathrm{~m}^{-2}$ were added to 'observed' LST and LAI, respectively. Sensitivity indices (SI) are then computed based on the partial derivatives of the output results with respect to change in input caused by the implemented random noise, using eq. 21 adapted from van

350 Griensven et al. (2006).

$$
S I=\frac{\frac{M\left(\Delta \rho_{i}+\rho_{j}+\cdots+\rho_{k}\right)-M\left(\rho_{i}+\rho_{j}+\cdots+\rho_{k}\right)}{M\left(\rho_{i}+\rho_{j}+\cdots+\rho_{k}\right)}}{\frac{\Delta \rho_{i}}{\rho_{i}}}
$$


where $\mathrm{M}$ is model output; $\rho$ refers to the different model inputs; $\Delta \rho_{i}$ refers to the pertubation of the input caused by artificial noise. The SI is based on the change observed for modeled $\mathrm{H}$.

The input SA was tested with both canopy wind attenuation sub-models (i.e. $\mathrm{TSEB}_{\mathrm{G}}-\mathrm{DF}$ and $\mathrm{TSEB}_{\mathrm{M}}-\mathrm{DF}$ ) for 365 days (during 2015) with a 30-min time step. Since TSEB incorporates LAI at the daily time scale, the SI is derived based on the daily aggregated absolute change in $\mathrm{H}$ in relation to the absolute change in LAI for that day. For the LST analysis, the effect of a deviation in LST on the resulting $\mathrm{H}$ will likely be impacted by the hour in which the deviation occurs (i.e. a perturbation in LST during night time will likely impact $\mathrm{H}$ differently compared to a daytime perturbation). To normalize the time of perturbation, for each simulation day, only the mean net perturbation of LST during midday (between 11:00 and 13:00 UTC)

360 was used to analyze the net effect on H during that same time period. Hence, SIs for both LAI and LST are derived for each daily time step using the absolute change in inputs with the resulting absolute change in output.

\subsubsection{End Member Simulations}

In addition to the default simulations, two 'end member' scenarios were conducted as limiting case studies. The first case assumes a pure grassland, ignoring the tree components, for the entire year (hereafter as $\mathrm{TSEB}_{\text {grass }}$ ). The second case ignores

365 the grass layer, simulating the vegetated component as a scattered, clumped evergreen broadleaf forest (hereafter as $\left.\mathrm{TSEB}_{\text {tree}}\right)$. The estimation of the roughness characteristics differed for each scenario as described in section 2.2.2, parameters related to the resistances in $\mathrm{TSEB}_{\text {tree }}$ were changed to mimic sparsely vegetated and rough soil conditions (Kustas et al., 2016), where specific parameter values are shown in table 3. These scenarios were performed on the CT tower during 2015.

Table 3. TSEB-DF, $\mathrm{TSEB}_{\text {grass }}$ and $\mathrm{TSEB}_{\text {tree }}$ model configurations with the different parameter values

\begin{tabular}{lc|c|c}
\hline Parameters & TSEB-DF & \multicolumn{2}{c}{ End-Member } \\
& & TSEB $_{\text {grass }}$ & TSEB $_{\text {tree }}$ \\
\hline \hline$\alpha_{P T}(-)$ & 1.26 & 1.26 & 1.26 \\
$f_{g}(-)$ & 0.7 & 0.7 & 0.9 \\
$f_{C}(-)$ & 0.8 & 0.8 & 0.2 \\
$w_{C}(-)$ & 1 & 1 & 1 \\
$X_{L A D}(-)$ & 1 & 1 & 1 \\
$h_{c}(\mathrm{~m})$ & 8 & 0.5 & 8 \\
$z 0_{\text {soil }}(\mathrm{m})$ & 0.01 & 0.01 & 0.01 \\
$l_{w}(\mathrm{~m})$ & 0.01 & 0.01 & 0.05 \\
$\mathrm{~b}(-)$ & 0.012 & 0.012 & 0.0605 \\
$C\left(\mathrm{~m} \mathrm{~s}^{-1} \mathrm{~K}^{-1 / 3}\right)$ & 0.0025 & 0.0025 & 0.0038 \\
$\mathrm{C}^{\prime}\left(\mathrm{s}^{1 / 2} \mathrm{~m}^{-1}\right)$ & 90 & 90 & 90 \\
\hline
\end{tabular}


https://doi.org/10.5194/hess-2019-354

Hydrology and

Preprint. Discussion started: 29 August 2019

(c) Author(s) 2019. CC BY 4.0 License.

\subsubsection{Two-Season modeling approach}

We propose here a two-season modeling approach (hereafter as TSEB-2S) that divides the annual simulation into two main phenological periods: a grass dominated growing period (i.e. grass-soil system) and a tree dominated summer/dry period (i.e. tree-soil system). This modeling scheme attempts to depict the considerable changes observed within the different seasonal periods. The differences in vegetation cover alter the turbulent conditions (i.e. roughness), radiation transmission (i.e. $f_{c}$ ) and, hence, the surface energy balance. The seasonal transition dates were estimated using an asymmetric gaussian filter over the NDVI time series, where the dry period was assumed to begin when vegetation (i.e. NDVI) begins to decay (downward inflection point) and the dry period ends when vegetation (i.e. NDVI) begins to re-green (upward inflection point). For instance, for the simulation year of 2015 , the dry period begins on May $13^{\text {th }}$ and ends on October $24^{\text {th }}$ (refer to appendix A, Fig.A3 for all transitions dates used)

380 The dry period is parameterized as a tree-soil system, assuming the grass has senesced. The $f_{c}$ is set to 0.2 (Oak trees represent roughly $20 \%$ of surface cover) and the roughness and resistances are calculated using tree characteristics (see section 2.2.2). By contrast, the growing period is parameterized ignoring the tree canopy and assuming a grass-soil system since the vegetation is dominated by grass (roughly 80\%) during this period (see table 3 ). This assumption is well supported by the evidences that the understory layer dominates LE in this site (Perez-Priego et al., 2018, 2017). A variable $f_{g}$, based on field measurements (appendix A, Fig.A2) is incorporated in the grass-soil configuration during the non-summer/growing periods. During the dry period, $f_{g}$ is constant and set to 0.9 since the trees have relatively constant foliage throughout the year, and less than 1 to account for branches and other non-green canopy material.

\subsubsection{Model evaluation}

To validate and benchmark model performance, the seasonally adapted TSEB-2S was independently tested on two nearby

EC towers within the study site (NT and NPT). El-Madany et al. (2018) demonstrated that, in the pre-fertilization phase, differences in biophysical surface properties caused differences in sub-hourly fluxes between the three nearby EC towers, identifying some level of spatial variability between the three sites. In the fertilization phase (2015-2017), differences in energy and water partitioning were observed (El-Madany et al., in preparation), and therefore it is interesting to test TSEB$2 \mathrm{~S}$ against the sites considering that they are structurally similar but show different response in terms of ecosystem functioning. The model was also benchmarked for different years (2016 and 2017) with different intra-annual dynamics. Therefore, an attempt was made to validate the TSEB-2S with independent model simulations for different spatial (three tower sites) and temporal (three different years) characteristics.

Additionally, an evaluation of model $L E$ partitioning, between $L E_{c}$ and $L_{s}$, was performed. $L_{s}$ was evaluated against independent lysimeter $\mathrm{LE}$ measurements $\left(\mathrm{LE}_{\mathrm{lys}}\right)$ at $\mathrm{CT}$ during dry summer periods, when grass is senesced and, thus, $\mathrm{LE}_{\mathrm{lys}}$ is assumed to be equivalent to soil evaporation (i.e. $\mathrm{LE}_{\mathrm{s}}$ ). For a detailed description of the lysimeter set-up in the Majadas 
https://doi.org/10.5194/hess-2019-354

Preprint. Discussion started: 29 August 2019

(c) Author(s) 2019. CC BY 4.0 License.

experimental site, refer to Perez-Priego et al. (2017). In addition, the TSEB-2S simulated $\mathrm{LE}_{\mathrm{c}}$ is benchmarked against that derived from a physiologically-based water flux partitioning approach, which allows for the separation of LE measured by EC into transpiration and evaporation components. The method was developed and validated in the same study site (PerezPriego et al., 2018).

\section{3. Results}

\subsection{TSEB sensitivity analysis}

\subsubsection{Sobol' parameter SA}

The parameter global SA showed that $f_{c}$ has the largest impact on model results, both as the main effect $\left(\mathrm{S}_{\mathrm{i}}\right)$ and through its interactions with other parameters $\left(\mathrm{S}_{\mathrm{T}}\right)$, regardless of the wind attenuation scheme applied (Fig. 3). Parameters related to

410 vegetated structure $\left(h_{c}\right)$ and cover $\left(f_{c}\right.$ and $\left.f_{g}\right)$ demonstrated the largest sensitivity. Notably, many parameters have insignificant first order sensitivities (close to 0 ) but relatively significant total order sensitivity, indicative of very important interactions between parameters. Parameters related to Massman et al. (2017)'s wind attenuation scheme ( $\mathrm{h}_{\max }, \mathrm{X}_{\mathrm{i}, \text { soil }}$, and $\left.\mathrm{C}_{\mathrm{d}}\right)$ depicting canopy shape and its effect on wind speed, showed very little direct influence on output variance, but important interactions with other parameters are observed. 
https://doi.org/10.5194/hess-2019-354

Preprint. Discussion started: 29 August 2019

(c) Author(s) 2019. CC BY 4.0 License.
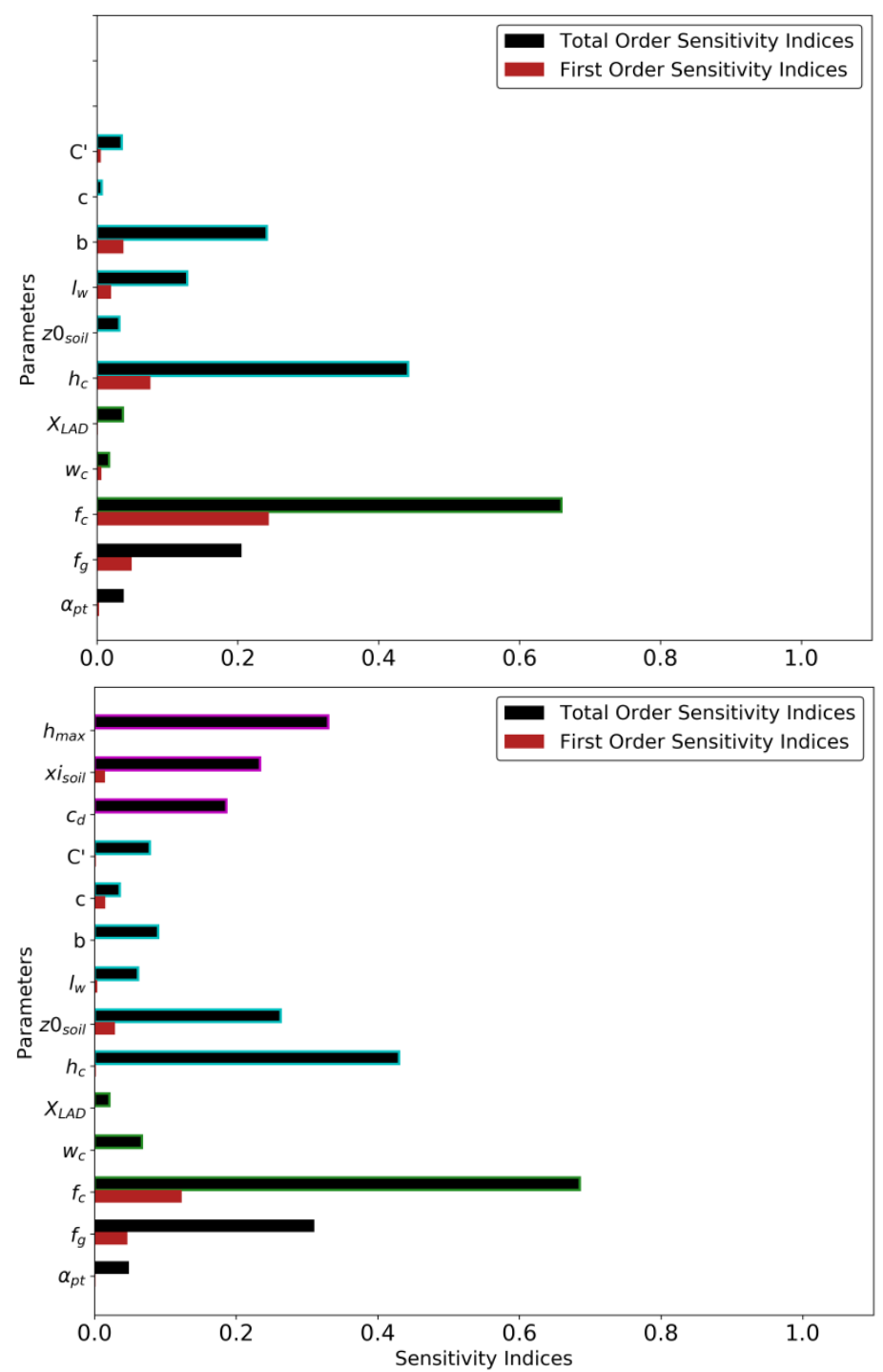

Figure 3. First $\left(\mathrm{S}_{\mathrm{i}}\right)$ and total $\left(\mathrm{S}_{\mathrm{T}}\right)$ order $\mathrm{SI}$ for the main parameters in the $\mathrm{TSEB}_{\mathrm{G}}-\mathrm{DF}$ (top) and $\mathrm{TSEB}_{\mathrm{M}}$-DF (bottom).

\section{$425 \quad 3.1 .2$ Input local SA}

Uncertainties related to LST and LAI showed significant impacts on model results (Fig. 4). Simulated H is particularly sensitive to deviations in LST, where differences of a unit change of LST $(\Delta 1 \mathrm{~K})$ is associated to a median $15.1 \%$ and $15.4 \%$ change in modelled $\mathrm{H}$ for $\mathrm{TSEB}_{\mathrm{G}}-\mathrm{DF}$ and $\mathrm{TSEB}_{\mathrm{M}}$-DF, respectively. In terms of relative change, a $1 \%$ variation in LST (i.e $\Delta$ $3 \mathrm{~K}$ for a $300 \mathrm{~K}$ surface) is associated with a median change of $45.7 \%$ and $46.4 \%$ in modelled $\mathrm{H}$ for TSEB $\mathrm{G}_{\mathrm{G}}-\mathrm{DF}$ and $\mathrm{TSEB}_{\mathrm{M}^{-}}$ 430 DF, respectively. The uncertainty in LAI demonstrated, compared to LST, less influence on H but nonetheless significant. 
https://doi.org/10.5194/hess-2019-354

Preprint. Discussion started: 29 August 2019

(c) Author(s) 2019. CC BY 4.0 License.

The change in LAI of $\Delta 0.1 \mathrm{~m}^{2} / \mathrm{m}^{2}$ is associated with $3.3 \%$ and $4.3 \%$ change in estimated $\mathrm{H}$ with $\mathrm{TSEB}_{\mathrm{G}}-\mathrm{DF}$ and $\mathrm{TSEB}_{\mathrm{M}}-\mathrm{DF}$, respectively. In terms of percent change, a $1 \%$ change in LAI is associated with a median change of $0.31 \%$ and $0.42 \%$ in modeled $\mathrm{H}$ for $\mathrm{TSEB}_{\mathrm{G}}-\mathrm{DF}$ and $\mathrm{TSEB}_{\mathrm{M}}-\mathrm{DF}$, respectively.
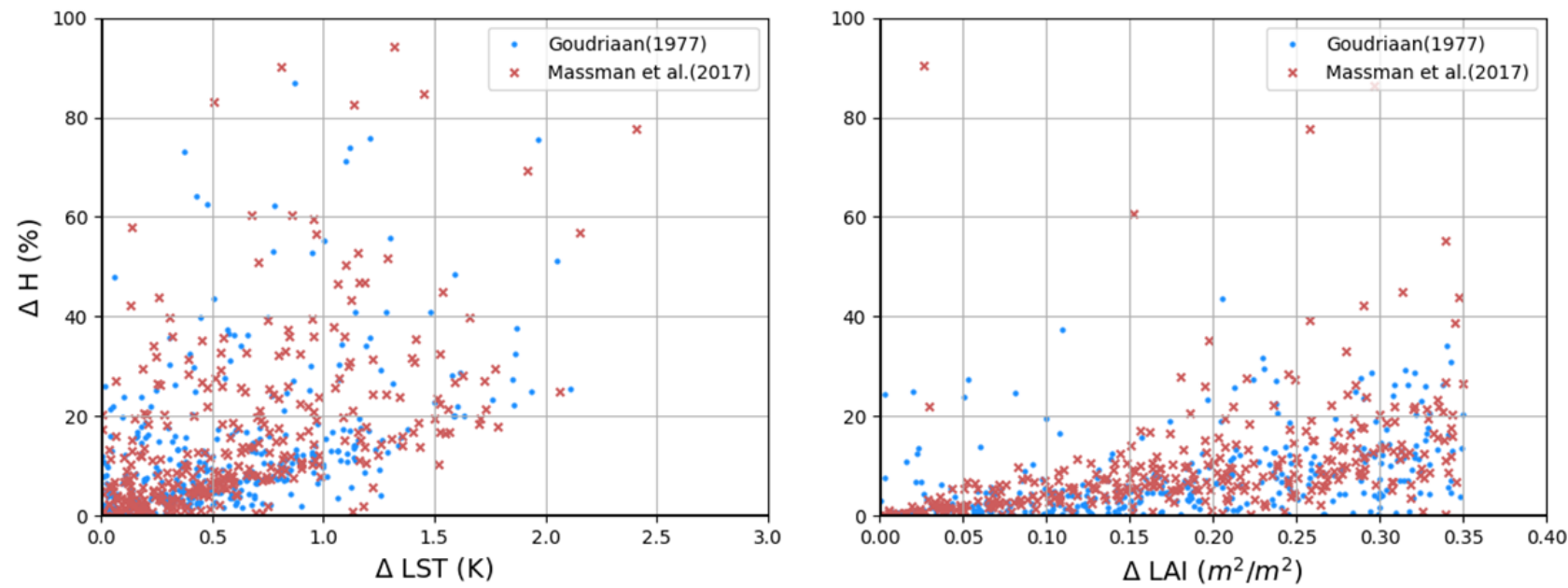

Figure 4. Scatter plots of the absolute percent change in daily aggregated $\mathrm{H}$ (y-axis) with the associated absolute perturbation of the daily aggregated input (x-axis): LST (left) and LAI (right) using $\mathrm{TSEB}_{\mathrm{G}}-\mathrm{DF}$ (blue) and $\mathrm{TSEB}_{\mathrm{M}}-\mathrm{DF}$ (red)

\subsection{Model simulations}

\subsubsection{TSEB-DF, TSEB grass, $_{\text {TSEB }}$ tree}

Model results of default TSEB using Goudriaan's wind attenuation scheme (TSEB $\mathrm{G}_{\mathrm{G}}-\mathrm{DF}$ ) vastly underestimate H (bias: -39

$440 \mathrm{~W} \mathrm{~m}^{-2}$ ) and, consequently, overestimate LE (bias: $34 \mathrm{~W} \mathrm{~m}^{-2}$ ) as compared with observed EC data. As shown in Fig. 5, high errors are observed throughout (RMSD of $\mathrm{H}: 76 \mathrm{~W} \mathrm{~m}^{-2}$ ) but errors stem particularly from the very significant underestimations of $\mathrm{H}$ during the hot and dry summer period (Fig. 5).
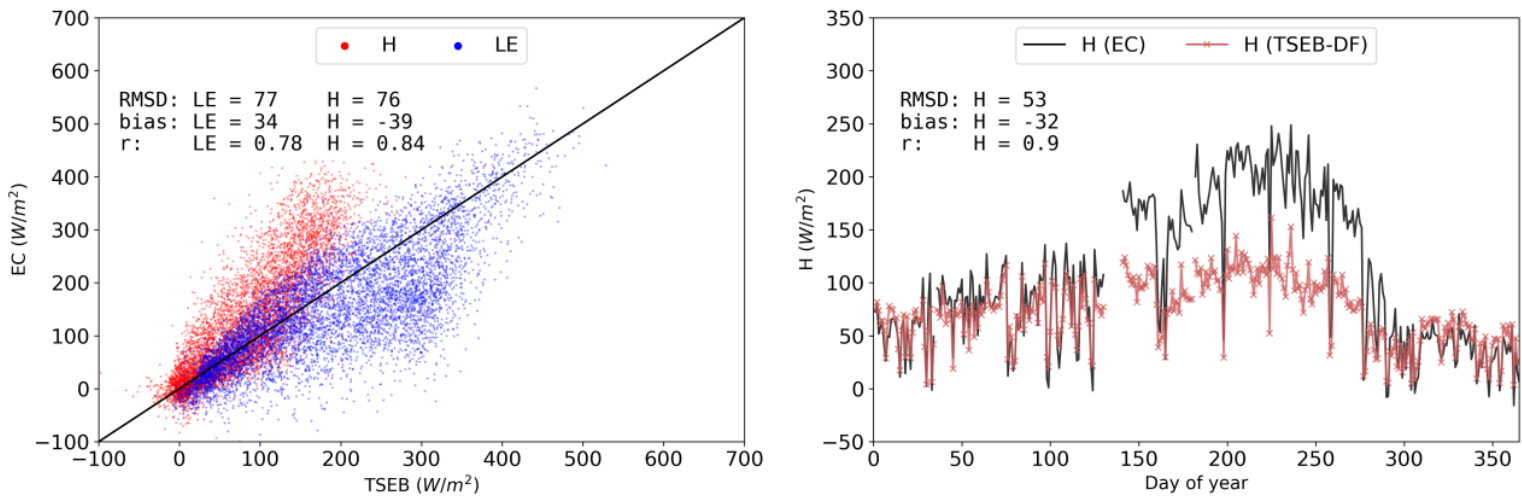

Figure 5. Observed vs modeled daytime half-hourly H (red) and LE (blue) density scatterplot (left) and time series of simulated (red) and

observed (black) daytime daily mean $\mathrm{H}$ (right) for $\mathrm{TSEB}_{\mathrm{G}}$-DF in 2015 at CT 
The end member simulations demonstrate the 'boundary conditions' when, with the same inputs, the simulations completely ignore one of the vegetation layers throughout the year. Predictably, TSEB $_{\text {grass }}$ underestimates $\mathrm{H}$ even more significantly than

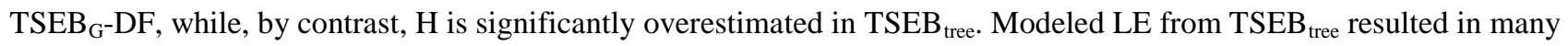
insignificant fluxes (i.e. $0 \mathrm{~W} \mathrm{~m}^{-2}$ ) even when the tower observed significant LE (Fig. 6). This indicates that, in many cases, an overestimated modeled $\mathrm{H}$ left no available energy flux for LE from the energy balance residual.
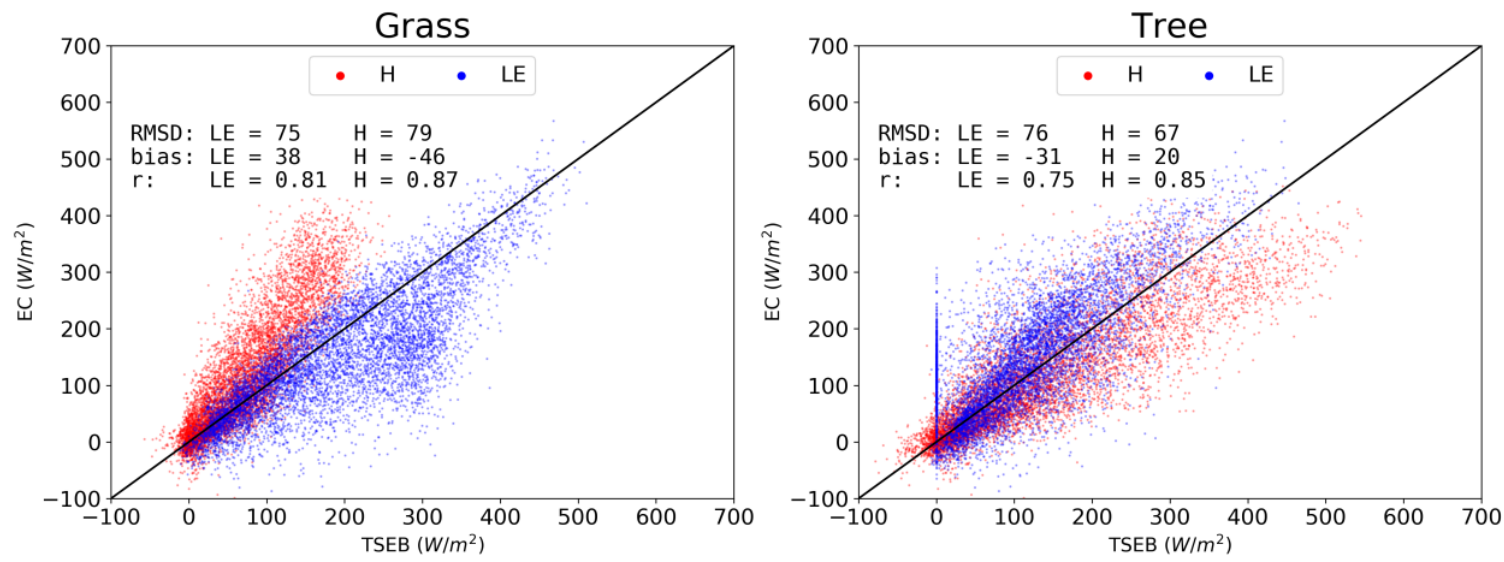

Figure 6. Observed vs modeled half-hourly daytime $\mathrm{H}$ (red) and LE (blue) density scatterplot for TSEB grass $_{\text {(left) and TSEB }}$ tree $($ right) in 2015 at CT

\subsubsection{TSEB-2S}

To improve the seasonal depiction and related changes to the ecosystem, the TSEB model was adapted using a two-season modeling approach as proposed in section 2.4.4. The global SA results showed that parameters related to the vegetation cover (i.e. $f_{c}$ and $f_{g}$ ) and structure (i.e $h_{c}$ ) had the most influence on model performance. Since these are physical and measureable parameters, these were simply set in each seasonal period according to the assumed dominant vegetation. The resistance coefficients $b$ and $c$, used in the formulation of $R_{s}$, were increased for the dry period, as was successfully tested and implemented in Kustas et al. (2016) (Table 4). In Kustas et al. (2016), $b$ and $c$ within TSEB were given a value of 0.0605 and 0.0038, respectively based on literature (Kondo and Ishida, 1997; Sauer et al., 1995) to consider rough soil and partially vegetated surfaces. Other parameters, such as $X_{L A D}$, which is presumably different for grasses and trees, were not modified since they showed little sensitivity (Fig. 3) 
https://doi.org/10.5194/hess-2019-354

Preprint. Discussion started: 29 August 2019

(c) Author(s) 2019. CC BY 4.0 License.

Table 4. TSEB-2S model configuration with different parameter values during the non-summer and summer periods

\begin{tabular}{l|l|l}
\hline Parameters & \multicolumn{2}{|c}{ TSEB-2S } \\
& Non-Summer & \multicolumn{1}{c}{ Summer } \\
\hline \hline$\alpha_{P T}(-)$ & 1.26 & 1.26 \\
$f_{g}(-)$ & $*$ & 0.9 \\
$f_{C}(-)$ & 0.8 & 0.2 \\
$w_{C}(-)$ & 1 & 1 \\
$X_{L A D}(-)$ & 1 & 1 \\
$h_{C}(\mathrm{~m})$ & 0.5 & 8 \\
$z 0_{\text {soil }}(\mathrm{m})$ & 0.01 & 0.01 \\
$l_{w}\left(\mathrm{~m}^{\prime}\right)$ & 0.01 & 0.01 \\
$\mathrm{~b}(-)$ & 0.012 & 0.0605 \\
$C\left(\mathrm{~m} \mathrm{~s}^{-1} \mathrm{~K}^{-1 / 3}\right)$ & 0.0025 & 0.0038 \\
$\mathrm{C}^{\prime}\left(\mathrm{s}^{1 / 2} \mathrm{~m}^{-1}\right)$ & 90 & 90 \\
\hline *Variable $f_{g}$ based on field data (appendix A, Fig.A2)
\end{tabular}

Simulations of LE and H for 2015 vastly improve using TSEB-2S with the Goudriaan (1977) wind attenuation scheme compared to $\mathrm{TSEB}_{\mathrm{G}}$-DF (Fig. 7). It yields a decrease in RMSD from $77 \mathrm{~W} \mathrm{~m}^{-2}$ and $76 \mathrm{~W} \mathrm{~m}^{-2}$ to $56 \mathrm{~W} \mathrm{~m}^{-2}$ and $52 \mathrm{~W} \mathrm{~m}^{-2}$ for $\mathrm{LE}$ and $\mathrm{H}$, respectively. The seasonal average daily $\mathrm{H}$ is well depicted from model results, particularly during the summer/dry period. The winter and spring period (roughly January to May) show a slight systematic $\mathrm{H}$ underestimation.

The two different wind attenuation models were applied within TSEB-2S but no significant changes occurred on overall model results when using the different wind profiles (Fig. 7). The magnitude of errors maintains relatively equal, only a slight decrease in RMSD $\left(56 \mathrm{Wm}^{-2}\right.$ to $54 \mathrm{Wm}^{-2}$ ) and slightly larger underestimation of $\mathrm{H}$ (bias of -3 to $-6 \mathrm{~W} \mathrm{~m}^{-2}$ ) was observed using the Massman et al. (2017) wind profile. Similar outcomes occur when comparing the different wind attenuation schemes across different periods, years and sites (Table 5). The largest difference in model performance occurs during the summer, particularly for NPT in 2015, when the canopy shape of the 'tree-soil' model scheme has a greater impact on the wind attenuation, and thus, H. However, for clarity purposes and since results barely change when using the 480 Massman et al. (2017) wind profile, including the LE partitioning (data not shown); the rest of the model evaluation in this study is concentrated on TSEB-2S with the Goudriaan (1977) wind profile scheme. 
https://doi.org/10.5194/hess-2019-354

Preprint. Discussion started: 29 August 2019

(c) Author(s) 2019. CC BY 4.0 License.
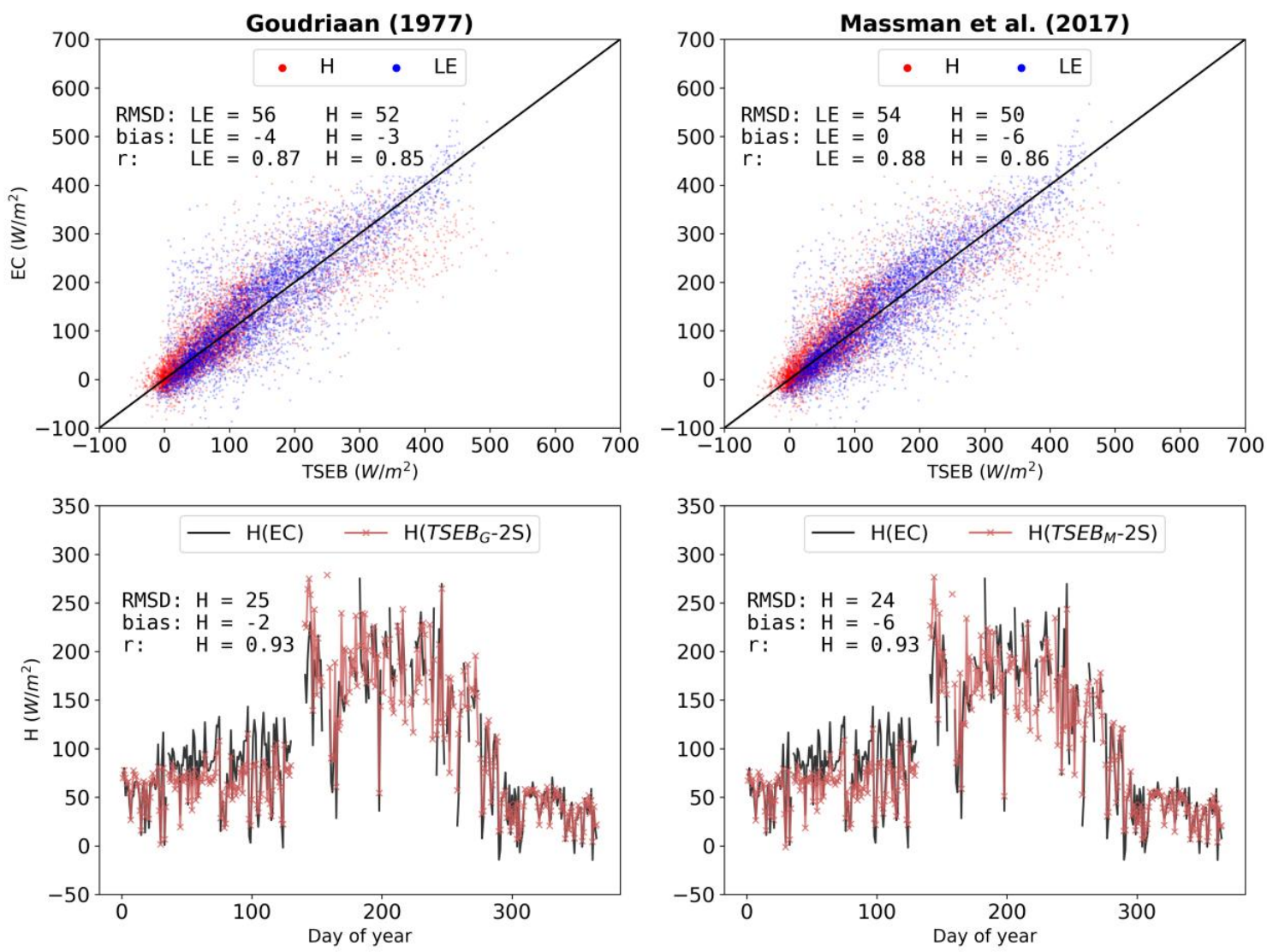

Figure 7. Observed vs modeled daytime half-hourly H (red) and LE (blue) density scatterplot (top) and time series of simulated (red) and observed (black) daytime daily mean H (bottom) for TSEB-2S simulations in 2015 at CT using Goudriaan (left) and Massman (right) 485 wind attenuation schemes 
https://doi.org/10.5194/hess-2019-354

Preprint. Discussion started: 29 August 2019

(c) Author(s) 2019. CC BY 4.0 License.

Table 5. Errors (RMSD and bias) are expressed in $\mathrm{W} \mathrm{m}^{-2}$ for modeled $\mathrm{H}$ using different wind attenuation schemes in TSEB-2S at CT, NT and NPT; and years 2015, 2016 and 2017; divided between growing and dry/summer periods. The 'Change' column refers to the absolute difference in metrics between using TSEB-2S with Goudriaan (1977) compared to Massman et al. (2017) (i.e. a change of -5 to -6 Wm ${ }^{-2}$ bias is a change of +1 )

\begin{tabular}{|c|c|c|c|c|c|c|c|c|c|c|c|}
\hline \multirow{2}{*}{ Year } & \multirow{2}{*}{ Season } & \multirow{2}{*}{ Tower } & \multicolumn{3}{|c|}{ Goudriaan (1977) } & \multicolumn{3}{|c|}{ Massman et al. (2017) } & \multicolumn{3}{|c|}{ Change } \\
\hline & & & $R M S D$ & Bias & $r$ & $R M S D$ & Bias & $r$ & $R M S D$ & Bias & $r$ \\
\hline \multirow{6}{*}{2015} & \multirow{3}{*}{ Growing } & CT & 37 & -9 & 0.81 & 37 & -10 & 0.81 & 0 & +1 & 0 \\
\hline & & NT & 41 & -13 & 0.80 & 41 & -15 & 0.80 & 0 & +2 & 0 \\
\hline & & NPT & 45 & -21 & 0.80 & 45 & -22 & 0.80 & 0 & +1 & 0 \\
\hline & \multirow{3}{*}{ Dry } & CT & 71 & 6 & 0.83 & 67 & -2 & 0.84 & -4 & -4 & +0.01 \\
\hline & & NT & 71 & 3 & 0.84 & 68 & -6 & 0.85 & -3 & +3 & +0.01 \\
\hline & & NPT & 77 & 7 & 0.82 & 69 & -16 & 0.83 & -8 & +9 & +0.01 \\
\hline \multirow{6}{*}{2016} & \multirow{3}{*}{ Growing } & CT & 40 & -6 & 0.76 & 40 & -8 & 0.77 & 0 & +2 & +0.01 \\
\hline & & NT & 37 & -8 & 0.80 & 38 & -12 & 0.80 & +1 & +4 & 0 \\
\hline & & NPT & 39 & -12 & 0.79 & 41 & -16 & 0.78 & +2 & +4 & -0.01 \\
\hline & \multirow{3}{*}{ Dry } & $\mathrm{CT}$ & 70 & 0 & 0.83 & 69 & -5 & 0.82 & -1 & +5 & -0.01 \\
\hline & & NT & 67 & -3 & 0.84 & 68 & -9 & 0.83 & +1 & +6 & -0.01 \\
\hline & & NPT & 72 & -11 & 0.82 & 74 & -15 & 0.81 & +2 & +4 & -0.01 \\
\hline \multirow{6}{*}{2017} & \multirow{3}{*}{ Growing } & CT & 39 & -14 & 0.86 & 39 & -15 & 0.87 & 0 & +1 & +0.01 \\
\hline & & NT & 44 & -21 & 0.87 & 44 & -22 & 0.87 & 0 & +1 & 0 \\
\hline & & NPT & 33 & -9 & 0.91 & 34 & -13 & 0.90 & +1 & +4 & -0.01 \\
\hline & \multirow{3}{*}{ Dry } & CT & 61 & -1 & 0.85 & 57 & -7 & 0.86 & -4 & +6 & +0.01 \\
\hline & & NT & 62 & -23 & 0.86 & 64 & -28 & 0.87 & +2 & +5 & +0.01 \\
\hline & & NPT & 59 & -13 & 0.87 & 60 & -17 & 0.87 & +1 & +4 & 0 \\
\hline
\end{tabular}

\subsection{TSEB-2S Model Evaluation}

\section{$500 \quad$ 3.3.1 Spatial and temporal evaluation}

TSEB-2S was additionally tested for the NT and NPT EC towers in 2016 and 2017. The results from the other sites and years are very satisfactory (Fig. 8), with errors are comparable to the 2015 simulation at the CT. RMSD for H ranges between 50 and $60 \mathrm{~W} \mathrm{~m}^{-2}$ between all validating simulations. The model demonstrates robustness, able to simulate adequately for different temporal periods and conditions (i.e. nutrient fertilization effects on the NT and NPT sites). 
https://doi.org/10.5194/hess-2019-354

Preprint. Discussion started: 29 August 2019

(c) Author(s) 2019. CC BY 4.0 License.
Hydrology and Earth System Sciences

Discussions
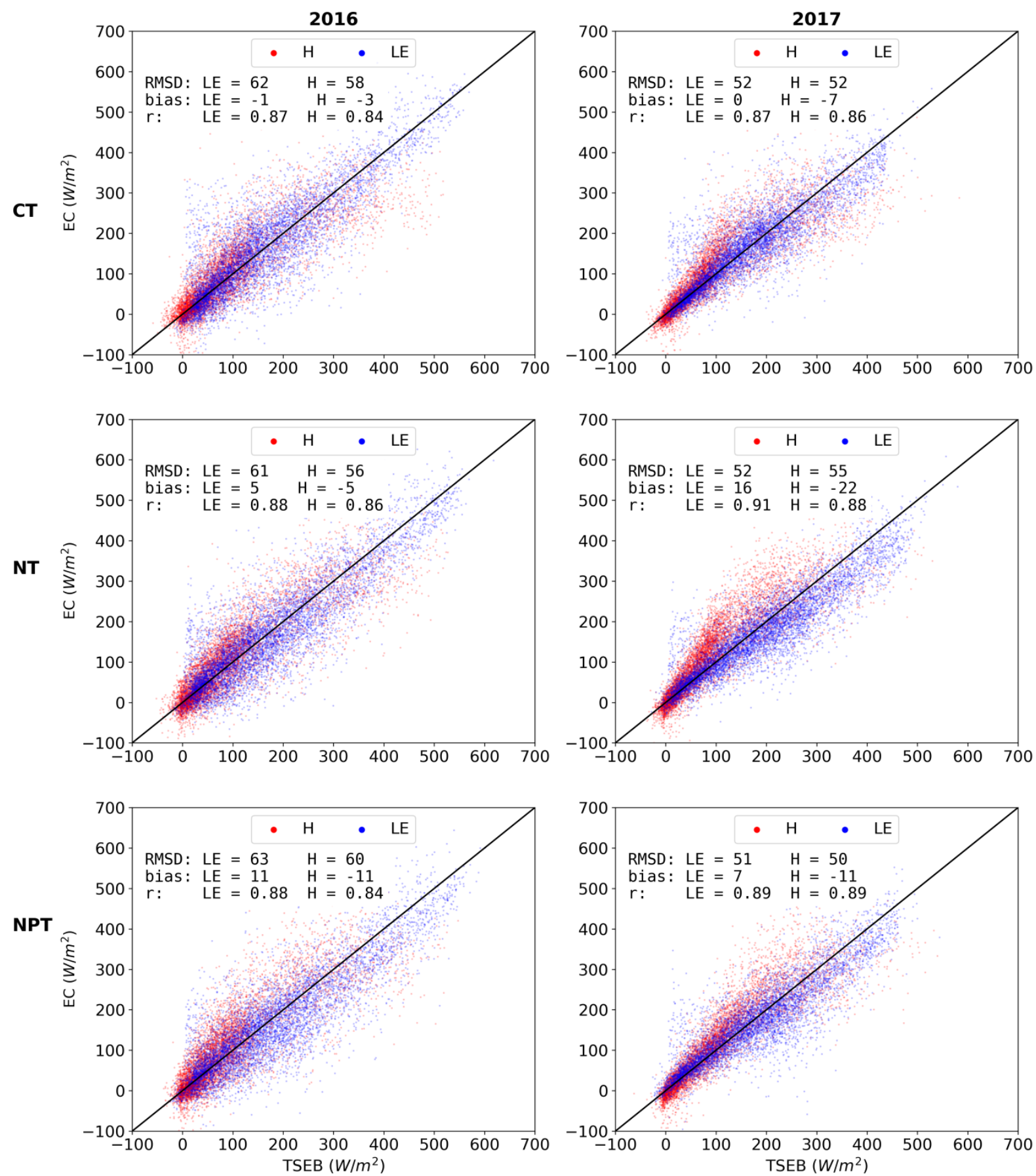

Figure 8. Observed vs modelled daytime half-hourly H (red) and LE (blue) density scatterplot for TSEB-2S for CT, NT and NPT; and years 2016 and 2017. 


\subsubsection{LE partitioning}

The LE partitioning in TSEB-2S was evaluated against independent estimates from the lysimeter at the CT footprint during the summer drought, when there is no grass transpiration and, thus, LE measured by the lysimeter $\left(\mathrm{LE}_{\mathrm{lys}}\right)$ corresponds to soil evaporation (Perez-Priego et al., 2018, 2017). It was additionally compared against an EC LE partitioning method (PerezPriego et al., 2018). Results indicate a systematic $\mathrm{LE}_{\mathrm{s}}$ underestimation during the dry period for the three years analyzed

515 (Fig. 9). The $\mathrm{LE}_{\mathrm{s}}$ overestimation is particularly significant for 2015 (bias: $-28 \mathrm{~W} \mathrm{~m}^{-2}$ ). In 2017, modeled $\mathrm{LE}_{\mathrm{s}}$ is most aligned against the fluxes measured by the lysimeter with less, while still significant, errors (RMSD: $25 \mathrm{~W} \mathrm{~m}^{-2}$; bias: $-13 \mathrm{~W} \mathrm{~m}^{-2}$ ). TSEB-2S, while having a systematic offset, was able to capture the temporal dynamics very well, as illustrated by effectively capturing the evaporation peaks caused by the rare summer precipitation events in 2016 and 2017.
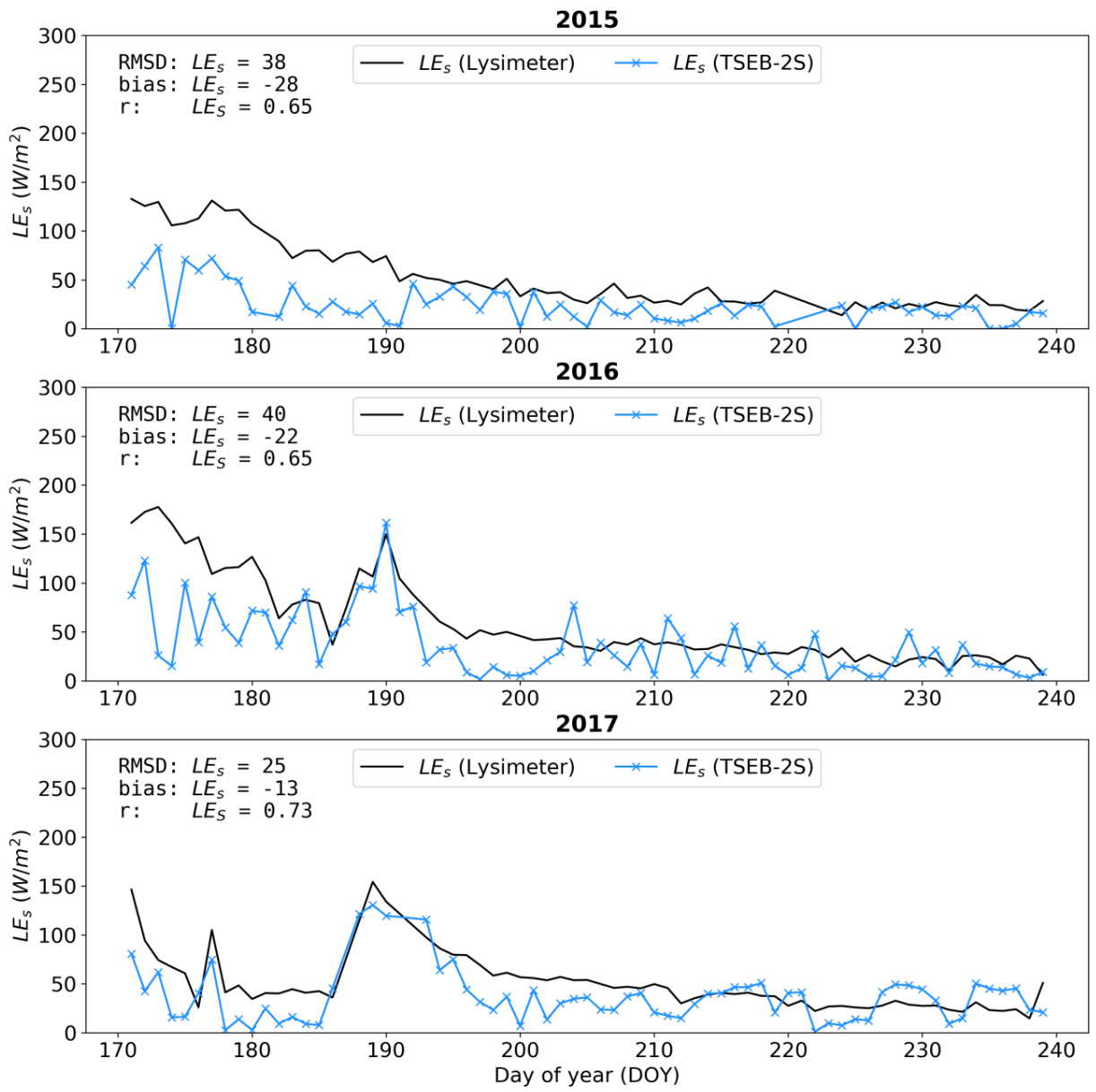

520 Figure 9. Time series of simulated (blue) and observed (black) daytime daily mean $\mathrm{LE}_{\mathrm{s}}$ at CT during the peak summer in 2015 , 2016 and 2017 using TSEB-2S. LE measured by the lysimeter is assumed to be equivalent to $\mathrm{LE}_{\mathrm{s}}$ during the summer period due to grass senescence. 
The $\mathrm{LE}_{\mathrm{c}}$ overestimation in the summer is also supported when comparing TSEB-2S derived $\mathrm{LE}_{\mathrm{c}}\left(\mathrm{LE}_{\mathrm{c}, \mathrm{TSEB}-2 \mathrm{~s}}\right)$ with transpiration estimates based on Perez-Priego et al. (2018) (LE $\mathrm{E}_{\mathrm{c}, \mathrm{PP}}$ ) (Fig. 10). Throughout most of the year, $\mathrm{LE}_{\mathrm{c}, \mathrm{TSEB}-2 \mathrm{~S}}$ has a positive bias compared to $\mathrm{LE}_{\mathrm{c}, \mathrm{PP}}$. However, patterns significantly and drastically change during the dry period, where $\mathrm{LE}_{\mathrm{c}, \mathrm{TSEB}-2 \mathrm{~S}}$ is more in line with $\mathrm{LE}_{\mathrm{c}, \mathrm{PP}}$ (less significantly in 2017). Since $\mathrm{LE}_{\mathrm{c}, \mathrm{PP}}$ contains both tree and grass contribution, the $\mathrm{LE}_{\mathrm{c}, \mathrm{PP}}$ peak is more sustained than $\mathrm{LE}_{\mathrm{c}, \mathrm{TSEB}-2 \mathrm{~S}}$. This is explained by the successive influence of the grass (DOY 90) followed by the trees in late-May/early-June(DOY 150) and then have a gradual decline during the dry-down as modulated by water stress. By contrast, $\mathrm{LE}_{\mathrm{c}, \mathrm{TSEB}-2 \mathrm{~s}}$ peaks earlier, around late-April, and proceeds to decline very rapidly when summer begins, coinciding with the change in model configuration between the grass-soil system to the tree-soil system. $\mathrm{LE}_{\mathrm{c}, \mathrm{TSEB}-2 \mathrm{~S}}$ also shows a steady increase beginning towards the end of summer (roughly September, DOY 250) until the autumn re-greening (roughly late-October, DOY 300), which is less significantly observed in $\mathrm{LE}_{\mathrm{c}, \mathrm{PP}}$.
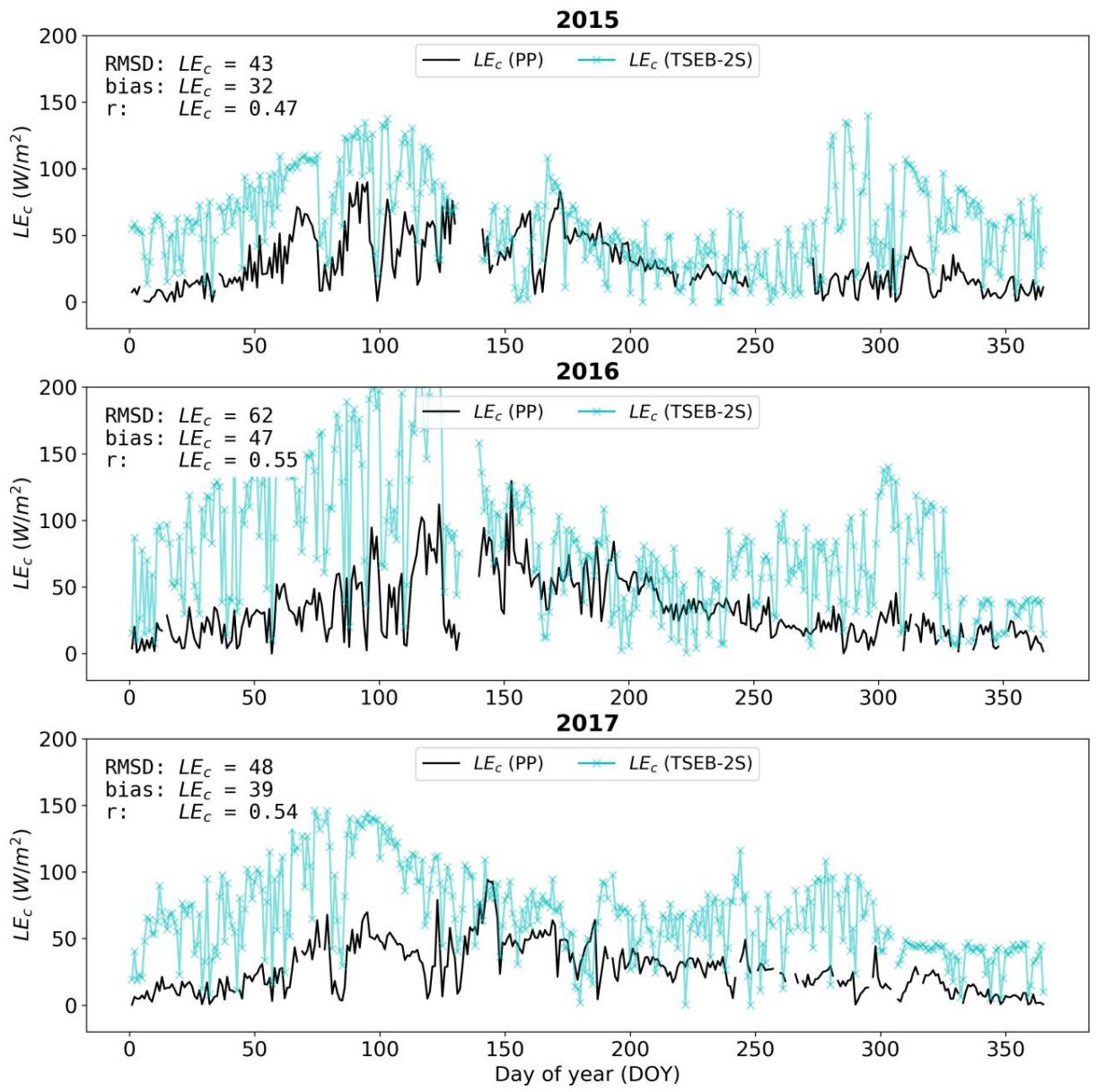

Figure 10. Annual time series of simulated $\mathrm{LE}_{\mathrm{c}, \mathrm{TSEB}-2 \mathrm{~S}}$ (blue) and estimated $\mathrm{LE}_{\mathrm{c}, \mathrm{PP}}$ (black) daytime daily mean $\mathrm{LE}_{\mathrm{c}}$ at $\mathrm{CT}$ in 2015 , 2016 and 2017 


\section{Discussion}

TSEB-2S significantly improved model performance in simulating LE and H compared to the default TSEB (Fig. 7). The simple assumption of two separate phenological periods, one dominated by a grass-soil system and the other dominated by a tree-soil system, permits the successful application of a two-layer model in an essentially three (soil-grass-tree) layer ecosystem. The results also demonstrate that significant changes to the vegetated surface have a very important influence on the surface energy balance. This confirms the importance of vegetation characteristics in controlling ecosystem level energy fluxes, where seasonal dynamics and phenology of vegetation are key considerations for land-atmospheric modeling. The TSEB-2S model demonstrated robustness, being able to successfully simulate different intra-annual dynamics for various

545 years and towers with distinct surface conditions from the nutrient fertilization experiment (Fig. 8). Results and the associated magnitudes of errors for all model runs are similar to the error bounds found in other energy balance model studies (e.g. Andreu et al., 2018; Boulet et al., 2015; Gan and Gao, 2015; Gonzalez-Dugo et al., 2009; Guzinski et al., 2014; Kustas et al., 2016; Kustas and Norman, 1999; Timmermans et al., 2007).

The global SA demonstrated that TSEB is most sensitive to $f_{c}$. This is largely due to $f_{c}$ being a key input to estimate the $\Omega$ (Kustas and Norman, 1999), which in turn affects the radiation interception and partitioning between the mixed vegetated and soil surfaces. The estimation of $\Omega$ is mostly based on the transmission through the vegetated layer where $f_{c}$ is used to obtain a local LAI $\left(\mathrm{LAI} / f_{c}\right)$ and as an important weighting factor for the gap fraction estimation (section 2.2.1). These results are largely in line with results from $\mathrm{Li}$ et al. (2005), who found that the $\Omega$ uncertainties had a significant impact on flux outputs from TSEB. They tested incremental $f_{c}$ values, between 0.1 and 1 , that resulted in sharp $\mathrm{H}$ changes, particularly between higher $f_{c}$ values, an indication of a high sensitivity for this parameter. The $f_{g}$ is more sensitive compared to $\alpha_{P T}$ even though both parameters are part of the initial canopy transpiration estimate from the Priestly-Taylor formulation (eq. 7). This is the case since the latter is merely an initial value and is iteratively changed through the modeling scheme, if the resulting soil evaporation flux is unrealistic. The $b$ coefficient was the only more empirically derived parameter that demonstrated relatively large influence. This was more significantly observed within TSEB $_{\mathrm{G}}-\mathrm{DF}$ since the Massman et al. (2017) wind profile decreases asymptotically to 0 near the soil therefore the term $b u_{s}$ has less influence than $c\left(T_{s}-T_{c}\right)^{1 / 3}$ for the $R_{S}$ estimation (eq. 11) compared to the Goudriaan (1977) wind profile where $u_{s}$ tends to 0 .

The input SA showed that uncertainties in LST and LAI both translate relatively significantly into uncertainties in the modeled H. Gan and Gao (2015) also found TSEB to be quite sensitive to biases in LST, where a $1 \mathrm{~K}$ change is associated with median daily $\sim 12-25 \mathrm{~W} \mathrm{~m}^{-2}$ bias. The sensitivity of modeled $\mathrm{H}$ to LAI uncertainties were slightly more pronounced with $\mathrm{TSEB}_{\mathrm{M}}$-DF compared to $\mathrm{TSEB}_{\mathrm{G}}$-DF (Fig. 4). This is the case since LAI is additionally used in the Massman et al. (2017) wind attenuation scheme, to characterize the canopy shape and its effect on the wind profile. A local LAI SA in Li et 
https://doi.org/10.5194/hess-2019-354

Hydrology and

Preprint. Discussion started: 29 August 2019

(c) Author(s) 2019. CC BY 4.0 License.

al. (2005) added $+-20 \%$ deviation to LAI and investigated the associated relative $\mathrm{H}$ change in TSEB. Their associated $\sim 3-8 \%$ bias in modeled $\mathrm{H}$ is largely in line with results presented here, with a $20 \%$ change in LAI associated with a median $\mathrm{H}$ bias of $6.1 \%$ and $8.4 \%$ for $\mathrm{TSEB}_{\mathrm{G}}-\mathrm{DF}$ and $\mathrm{TSEB}_{\mathrm{M}}-\mathrm{DF}$, respectively.

570 Overall model results using the different wind attenuation schemes were very similar, without significant change in modeled fluxes. For some years, the use of Massman et al. (2017) marginally decreased the resulting errors, while for other years it marginally increased errors (Table 5). This is in line with Nieto et al. (2019), who investigated the effect of the same two wind attenuation schemes on TSEB over a grapevine in a semi-arid region in California. Very little difference in model performance was found between the annual error statistics. However, Nieto et al. (2019) found a relatively significant reduction of errors in modeled $\mathrm{H}$ with Massman et al. (2017) during the spring seasonal period, when the grapevine canopy was most vertically clumped. Similarly, Table 5 shows that Massman et al. (2017) tends to have a more significant effect during the summer period. This is due to the model configuration as the growing period is parameterized as a homogenous grass layer and, thus, the canopy shape should not have a large impact on the wind attenuation. However, errors tend to increase in the summer for Massman et al. (2017), notably in 2015 for NPT. The overall benefit of using Massman et al. (2017) within TSEB is not conclusive through these results. It does not significantly impact overall model results, unless a very large influence of canopy vertical density is expected. These results, along with the SA, indicate that correctly partitioning incoming radiation, such as characterizing vegetation clumping, has a much stronger influence on model performance compared to accurately modeling the wind profile through the canopy.

As shown, bulk (soil + vegetation) fluxes were well modeled in TSEB-2S for different years and towers. However, the partitioning of $L E$, between $\mathrm{LE}_{\mathrm{s}}$ and $\mathrm{LE}_{\mathrm{c}}$, has greater uncertainty, with biases observed compared to the lysimeter measurements (Fig. 9) and compared to a physiologically-based EC partitioning method (Fig. 10). Since total LE is well modeled, this indicates errors associated with the partitioning itself. The partition of LE is largely controlled through LAI within TSEB (Kustas et al., 2019), as evidenced in how the LE $_{c}$ time series (Fig. 9) roughly follows the trend of the LAI input time series shown in appendix A (Fig. A3). The rapid decrease in LAI as the summer begins results in a rapid change in $\mathrm{LE}_{\mathrm{c}, \mathrm{TSEB}-2 \mathrm{~S}}$, in contrast to the gradual decrease of $\mathrm{LE}_{\mathrm{c}, \mathrm{PP}}$. This can also be attributed to TSEB-2S's sudden change in model configuration (i.e. from grass to tree dominated). The transition periods between model configurations had the largest biases (roughly around DOY 120 and DOY 300) while the dry period, when the model considers only the tree-soil system, produced the best simulated LE partitions. TSEB's relatively poor performance in partitioning LE were also observed over a vineyard in Kustas et al. (2019). However, Xu et al. (2016) reported a relatively good performance of TSEB's midday LE partitioning over an irrigated cropland against observations using the isotope approach. Colaizzi et al. (2014) demonstrated that using the Penman-Monteith equation to derive initial canopy transpiration in TSEB resulted in a better agreement with $\mathrm{LE}_{\mathrm{s}}$ and $\mathrm{LE}_{\mathrm{c}}$ compared to the Priestley-Taylor approach. Colaizzi et al. (2014) also reported the strong influence of vapour pressure deficit over $\mathrm{LE}_{\mathrm{c}}$ in an irrigated cotton field within an advective, semi-arid climate, which was captured most 
https://doi.org/10.5194/hess-2019-354

Hydrology and

Preprint. Discussion started: 29 August 2019

(c) Author(s) 2019. CC BY 4.0 License.

successfully using the Penman-Monteith approach. As stated in Kustas et al. (2019), more studies need to evaluate whether the poor partitioning is linked to uncertainties in input values (i.e LAI) or biases caused by the modeling structure itself (i.e. initial potential canopy transpiration, radiation transfer).

As demonstrated, a simple adaptation to the modeling scheme within TSEB, depicting the seasonal changes in the ecosystem, were able to successfully simulate LE and $\mathrm{H}$ in a complex ecosystem. However, certain limitations are still present including the slight systematic underestimation of $\mathrm{H}$ during the grass growing season, particularly visible in 2015 (Fig. 7). This is likely due to the modeling scheme in this period ignoring the effect of the tree canopy layer on the turbulent transport and hence on the calculation of the aerodynamic resistances. Compared to grass layers, tree canopies are more aerodynamically coupled to the atmosphere and hence their aerodynamic resistance is lower, resulting in that trees can dissipate heat more efficiently (El-Madany et al., 2018). As discussed in El-Madany et al. (2018), tree canopies in the Majadas experimental site were an additional $\mathrm{H}$ source, even though they tend to have a lower LST than the grass layer. As such, ignoring the tree canopy during the growing periods may not adequately represent the aerodynamic resistance characteristics of the ecosystem resulting in $\mathrm{H}$ underestimations, in some cases. Further adaptations to TSEB model may be needed for the more operational and larger scale use of this model, notably for different complex systems such as TGEs. The differences between soil, grass and tree layers should inherently be integrated within the modeling structure to robustly consider their different geometric, physical and phenological properties and their resulting effect on energy fluxes. This was also hinted in Andreu et al. (2018), who incorporated different layers in a modified Goudriaan (1977) wind speed profile scheme to consider differences between tree and grass canopy layers for TGEs.

\section{Conclusions}

When accounting for different phenological periods, the TSEB model can provide robust LE and $\mathrm{H}$ estimations for a threelayered heterogeneous and semi-arid TGE. This confirms the important role that vegetation characteristics, notably its structure (i.e. $h_{c}$ ) and cover (i.e. $f_{c}$ and $f_{g}$ ), have on ecosystem level energy fluxes. The $f_{c}$ was the single most influential parameter on model performance, largely due to its role in characterizing vegetation clumping and how this, in turn, interacts significantly with other parameters. In addition, the uncertainties related to the traditionally remotely sensed derived inputs, LAI and LST, showed an important influence on output uncertainties.

The more physically-based wind attenuation scheme (Massman et al., 2017) had little impact on the overall modelled fluxes, especially compared to factors affecting the radiation budget between the two sources (i.e vegetation clumping). In addition, the LE partitioning, between canopy and soil, showed larger bias compared to the bulk fluxes, particularly during the transition towards the grass senescence period and the prominent contribution of the tree layer. Based on this, further research should focus on the understanding of the radiation partitioning between the canopy and soil layers, and, particularly, 
https://doi.org/10.5194/hess-2019-354

Preprint. Discussion started: 29 August 2019

(c) Author(s) 2019. CC BY 4.0 License.

inherently accounting for the important differences between soil, grass and tree layers of TGEs within the modeling

630 structure.

\section{Author contribution}

All authors contributed to discussing and improving the manuscript. MPM, HN, DR and VBL designed and formulated the research. MM and AC designed the experimental infrastructure. VBL analyzed the data, created the figures and wrote the manuscript. AC, MM, TSEM collected eddy covariance and biomet data. OPP collected, processed and provided lysimeter data. MPM sampled and analyzed field LAI samples.

The authors declare that they have no conflict of interest.

\section{Code and Data Availability}

EC, meteo and in-situ biophysical measurement data and related scripts necessary to run and evaluate model results are available via the online repository (link). The python script of the two-source energy balance model (TSEB) is freely

640 available via the link https://github.com/hectornieto/pyTSEB. The sensitivity analysis was performed using the Sensitivity Analysis Library (SALib) package in python, which is available via the link https://github.com/SALib/SALib. The ET partitioning code, as described in Perez-Priego et al. (2018), is implemented in R (R Development Core Team, 2010) and freely available via the link https://github.com/oscarperezpriego/ETpartitioning.

\section{Acknowledgements}

The project has received funding from the European Union's Horizon 2020 research and innovation programme under the Marie Sklodowska-Curie grant agreement No 721995.

This research was also funded by Ministerio de Economía y Competitividad through FLUXPEC CGL2012-34383 and SynerTGE CGL2015-G9095-R projects.

650 The research infrastructure at the measurement site Majadas de Tiétar was partly funded through the Alexander von Humboldt Foundation. 
https://doi.org/10.5194/hess-2019-354

Preprint. Discussion started: 29 August 2019

(c) Author(s) 2019. CC BY 4.0 License.

Hydrology and

Earth System

Sciences

Discussions

\section{References}

Alfieri, J.G., Kustas, W.P., Nieto, H., Prueger, J.H., Hipps, L.E., McKee, L.G., Gao, F., and Los, S.: Influence of wind direction on the surface roughness of vineyards, Irrigation Sci., 37, 359-373, https://doi.org/10.1007/s00271-0180610-z, 2019.

Allen, R., Tasumi, M., and Trezza, R.: Satellite-Based Energy Balance for Mapping Evapotranspiration with Internalized Calibration (METRIC) - Model, J. Irrig. Drain. Eng., 133, 380-394. https://doi.org/10.1061/(ASCE)07339437(2007)133:4(380), 2007.

Anderson, M.C., Norman, J.M., Kustas, W.P., Li, F., Prueger, J.H., and Mecikalski, J.R.: Effects of vegetation clumping on two-source model estimates of surface energy fluxes from an agricultural landscape during SMACEX, J. Hydrometeorol., 6, 892-909. 2005.

Andreu, A., Kustas, W., Polo, M., Carrara, A., and González-Dugo, M.: Modeling Surface Energy Fluxes over a Dehesa (Oak Savanna) Ecosystem Using a Thermal Based Two-Source Energy Balance Model (TSEB) I, Remote Sensing, 10(4), 567. https://doi.org/10.3390/rs10040567, 2018.

Baldocchi, D.D., Xu, L., and Kiang, N.: How plant functional-type, weather, seasonal drought, and soil physical properties alter water and energy fluxes of an oak-grass savanna and an annual grassland, Agricultural and Forest Meteorology, 123, 13-39, 2004.

Bastiaanssen, W., Menenti, M., Feddes, R., and Holtslag, A.: A remote sensing surface energy balance algorithm for land (SEBAL). 1. Formulation, Journal of Hydrology, 212, 198-212, 1998.

Beven, K.: Changing ideas in hydrology - The case of physically-based models, Journal of Hydrology, 105, 157-172. https://doi.org/10.1016/0022-1694(89)90101-7, 1989.

Bonan, G.B., and Doney, S.C.: Climate, ecosystems, and planetary futures: The challenge to predict life in Earth system models, Science, 359 (6375), eaam8328. https://doi.org/10.1126/science.aam8328, 2018.

Boulet, G., Mougenot, B., Lhomme, J.-P., Fanise, P., Lili-Chabaane, Z., Olioso, A., Bahir, M., Rivalland, V., Jarlan, L., Merlin, O., Coudert, B., Er-Raki, S., and Lagouarde, J.-P.: The SPARSE model for the prediction of water stress and evapotranspiration components from thermal infra-red data and its evaluation over irrigated and rainfed wheat, Hydrol. Earth Syst. Sc., 19, 4653-4672. https://doi.org/10.5194/hess-19-4653-2015, 2015.

Campbell, G.S., and Norman, J.M..: An Introduction to Environmental Biophysics, 2nd Edition, ed. Springer-Verlag New York, New York, 1998.

Casals, P., Gimeno, C., Carrara, A., Lopez-Sangil, L., and Sanz, Mj.: Soil CO2 efflux and extractable organic carbon fractions under simulated precipitation events in a Mediterranean Dehesa, Soil Biology and Biochemistry, 41, 1915-1922. https://doi.org/10.1016/j.soilbio.2009.06.015, 2009.

Colaizzi, P.D., Agam, N., Tolk, J.A., Evett, S.R., Howell Sr, T.A., O’Shaughnessy, S.A., Gowda, P.H., Kustas, W.P., and Anderson, M.C.: Advances in a two-source energy balance model: Partitioning of evaporation and transpiration for cotton, Transactions of the ASABE 59, 181-197, 2016.

Colaizzi, P.D., Agam, N., Tolk, J.A., Evett, S.R., Howell, T.A., Gowda, P.H., O’Shaughnessy, S.A., Kustas, W.P., and Anderson, M.C.: Two-source energy balance model to calculate E, T, and ET: Comparison of Priestley-Taylor and Penman-Monteith formulations and two time scaling methods. Transactions of the ASABE 57, 479-498, 2014.

Colaizzi, P.D., Evett, S.R., Howell, T.A., and Tolk, J.A.: Comparison of aerodynamic and radiometric surface temperature using precision weighing lysimeters, Remote sensing and modeling of ecosystems for sustainability, 5544, 215-230, International Society for Optics and Photonics. https://doi.org/10.1117/12.559503, 2004.

Diarra, A., Jarlan, L., Er-Raki, S., Le Page, M., Aouade, G., Tavernier, A., Boulet, G., Ezzahar, J., Merlin, O., and Khabba, S.: Performance of the two-source energy budget (TSEB) model for the monitoring of evapotranspiration over irrigated annual crops in North Africa, Agricultural Water Management, 193, 71-88. https://doi.org/10.1016/j.agwat.2017.08.007, 2017.

El-Madany, T.S., Reichstein, M., Carrara, A., Perez-Priego, O., Martín, M.P., Moreno, G., Martín, M.P., Pacheco-Labrador, J., Wohlfahrt, G., Nieto, H., Weber, U., Kolle, O., Luo, Y.-P., Carvalhais, N., and Migliavacca, M.: Drivers of spatio-temporal variability of carbon dioxide and energy fluxes in a Mediterranean savanna ecosystem, Agricultural and Forest Meteorology, 262, 258-278. https://doi.org/10.1016/j.agrformet.2018.07.010, 2018. 
https://doi.org/10.5194/hess-2019-354

Preprint. Discussion started: 29 August 2019

(c) Author(s) 2019. CC BY 4.0 License.

El-Madany, T.S., Reichstein, M., Carrara, A., Martín, M.P., Moreno, G., González-Cascón, R., Peñuelas, J., BurchardLevine, V., Hammer, T., Knauer, J., Kolle, O., Luo, Y.P., Pacheco-Labrador, J., Perez-Priego, O., Rolo, V., Wutzler, T., and Migliavacca, M.: Rapid shifts of ecosystem carbon and energy fluxes after nitrogen and phosphorus availability, in preperation.

Foken, T., Aubinet, M., Finnigan, J.J., Leclerc, M.Y., Mauder, M., and Paw U, K.T.: Results of a panel discussion about the energy balance closure correction for trace gases. Bulletin of the American Meteorological Society, 92, ES13ES18, 2011.

Friedl, M.A., Sulla-Menashe, D., Tan, B., Schneider, A., Ramankutty, N., Sibley, A., and Huang, X.: MODIS Collection 5 global land cover: Algorithm refinements and characterization of new datasets, Remote Sens. Environ., 114, 168$182,2010$.

Gan, G., and Gao, Y.: Estimating time series of land surface energy fluxes using optimized two source energy balance schemes: Model formulation, calibration, and validation, Agricultural and forest meteorology, 208, 62-75, 2015.

García, M., Gajardo, J., Riaño, D., Zhao, K., Martín, P., and Ustin, S.: Canopy clumping appraisal using terrestrial and airborne laser scanning, Remote Sens. Environ., 161, 78-88, 2015.

Gonzalez-Dugo, M.P., Neale, C.M.U., Mateos, L., Kustas, W.P., Prueger, J.H., Anderson, M.C., and Li, F.: A comparison of operational remote sensing-based models for estimating crop evapotranspiration, Agricultural and Forest Meteorology, 149, 1843-1853, 2009

Goudriaan, J.: Crop Micrometeorology: A Simulation Study, Center for Agricultural Publications and Documentation, Wageningen, 1977.

Guzinski, R., Anderson, M.C., Kustas, W.P., Nieto, H., and Sandholt, I.: Using a thermal-based two source energy balance model with time-differencing to estimate surface energy fluxes with day-night MODIS observations. Hydrol. Earth Syst. Sc., 17, 2809-2825, 2013.

Guzinski, R., Nieto, H., Jensen, R., Mendiguren, G.: Remotely sensed land-surface energy fluxes at sub-field scale in heterogeneous agricultural landscape and coniferous plantation. Biogeosciences, 11, 5021-5046, 2014

Herman, J. and Usher, W.: SALib: An open-source Python library for sensitivity analysis. Journal of Open Source Software, 2, 9, doi:10.21105/joss.00097, 2017.

Jasechko, S., Sharp, Z.D., Gibson, J.J., Birks, S.J., Yi, Y., and Fawcett, P.J.: Terrestrial water fluxes dominated by transpiration, Nature, 496, 347, 2013

Jin, X., Xu, C.-Y., Zhang, Q., and Singh, V.P.: Parameter and modeling uncertainty simulated by GLUE and a formal Bayesian method for a conceptual hydrological model, Journal of Hydrology, 383, 147-155. https://doi.org/10.1016/j.jhydrol.2009.12.028, 2010.

Kalma, J.D., McVicar, T.R., and McCabe, M.F.: Estimating Land Surface Evaporation: A Review of Methods Using Remotely Sensed Surface Temperature Data, Surv. Geophys., 29, 421-469. https://doi.org/10.1007/s10712-0089037-z, 2008.

Kljun, N., Calanca, P., Rotach, M.W., and Schmid, H.P.: A simple two-dimensional parameterisation for Flux Footprint Prediction (FFP). Geosci. Model Dev., 8, 3695-3713. https://doi.org/10.5194/gmd-8-3695-2015, 2015.

Kondo, J., and Ishida, S.: Sensible Heat Flux from the Earth's Surface under Natural Convective Conditions, J. Atmos. Sci., 54, 498-509, 1997.

Krinner, G., Viovy, N., de Noblet-Ducoudré, N., Ogée, J., Polcher, J., Friedlingstein, P., Ciais, P., Sitch, S., and Prentice, I.C.: A dynamic global vegetation model for studies of the coupled atmosphere-biosphere system, Global Biogeochemical Cycles, 19(1), https://doi.org/10.1029/2003GB002199, 2005.

750 Kustas, W.P., Alfieri, J.G., Anderson, M.C., Colaizzi, P.D., Prueger, J.H., Evett, S.R., Neale, C.M., French, A.N., Hipps, L.E., and Chávez, J.L.: Evaluating the two-source energy balance model using local thermal and surface flux observations in a strongly advective irrigated agricultural area, Advances in Water Resources, 50, 120-133, 2012.

Kustas, W.P., Alfieri, J.G., Nieto, H., Wilson, T.G., Gao, F., and Anderson, M.C., 2019, Utility of the two-source energy balance (TSEB) model in vine and interrow flux partitioning over the growing season, Irrig. Sci., 37, 375-388. https://doi.org/10.1007/s00271-018-0586-8, 2019

Kustas, W.P., and Anderson, M.C.: Advances in thermal infrared remote sensing for land surface modeling, Agricultural and Forest Meteorology, 149, 2071-2081, 2009. 
https://doi.org/10.5194/hess-2019-354

Preprint. Discussion started: 29 August 2019

(c) Author(s) 2019. CC BY 4.0 License.

Kustas, W.P., Nieto, H., Morillas, L., Anderson, M.C., Alfieri, J.G., Hipps, L.E., L.Villagarcía, Domingo, F., and García, M.: Revisiting the paper "Using radiometric surface temperature for surface energy flux estimation in Mediterranean drylands from a two-source perspective, Remote Sens. Environ., 184, 645-653, 2016.

Kustas, W.P., and Norman, J.M.: Evaluation of soil and vegetation heat flux predictions using a simple two-source model with radiometric temperatures for partial canopy cover, Agricultural and Forest Meteorology, 94, 13-29, 1999.

Li, F., Kustas, W.P., Prueger, J.H., Neale, C.M., and Jackson, T.J.: Utility of remote sensing-based two-source energy balance model under low-and high-vegetation cover conditions, J. Hydrometeorol., 6, 878-891, 2005.

LICOR Bioscience USA: LAI-2200 Plant Canopy Analyzer, Instruction Manual, 2011.

Lindroth, A.: Aerodynamic and canopy resistance of short-rotation forest in relation to leaf area index and climate, Boundary-Layer Meteorology, 66, 265-279, 1993.

Luo, Y., El-Madany, T., Filippa, G., Ma, X., Ahrens, B., Carrara, A., Gonzalez-Cascon, R., Cremonese, E., Galvagno, M., and Hammer, T.: Using Near-Infrared-Enabled Digital Repeat Photography to Track Structural and Physiological Phenology in Mediterranean Tree-Grass Ecosystems, Remote Sensing, 10, 1293, 2018.

Massman, W.J., Forthofer, J.M., Finney, M.A.: An improved canopy wind model for predicting wind adjustment factors and wildland fire behavior, Canadian Journal of Forest Research, 47, 594-603, https://doi.org/10.1139/cjfr-2016-0354, 2017.

McNaughton, K.G., and Van Den Hurk, B.J.J.M.: A "Lagrangian" revision of the resistors in the two-layer model for calculating the energy budget of a plant canopy, Boundary-Layer Meteorology, 74, 261-288, 1995.

Mendiguren, G., Pilar Martín, M., Nieto, H., Pacheco-Labrador, J., and Jurdao, S.: Seasonal variation in grass water content estimated from proximal sensing and MODIS time series in a Mediterranean Fluxnet site, Biogeosciences, 12, $5523-5535,2015$

Migliavacca, M., Perez-Priego, O., Rossini, M., El-Madany, T.S., Moreno, G., van der Tol, C., Rascher, U., Berninger, A., Bessenbacher, V., and Burkart, A.: Plant functional traits and canopy structure control the relationship between photosynthetic CO 2 uptake and far-red sun-induced fluorescence in a Mediterranean grassland under different nutrient availability, New Phytologist, 214, 1078-1091, 2017.

Migliavacca, M., Sonnentag, O., Keenan, T.F., Cescatti, A., O’Keefe, J., Richardson, A.D., 2012. On the uncertainty of phenological responses to climate change, and implications for a terrestrial biosphere model. Biogeosciences 9, 2063-2083. https://doi.org/10.5194/bg-9-2063-2012, 2012.

Nieto, H., Kustas, W.P., Alfieri, J.G., Gao, F., Hipps, L.E., Los, S., Prueger, J.H., McKee, L.G., and Anderson, M.C.: Impact of different within-canopy wind attenuation formulations on modelling sensible heat flux using TSEB. Irrig. Sci., 37, 315-331. https://doi.org/10.1007/s00271-018-0611-y, 2019.

Norman, J.M., Kustas, W.P., and Humes, K.S.: Source approach for estimating soil and vegetation energy fluxes in observations of directional radiometric surface temperature, Agricultural and Forest Meteorology, 77, 263-293, 1995.

Pacheco-Labrador, J., El-Madany, T.S., Martín, M.P., Migliavacca, M., Rossini, M., Carrara, A., and Zarco-Tejada, P.J.: Spatio-Temporal Relationships between Optical Information and Carbon Fluxes in a Mediterranean Tree-Grass Ecosystem, Remote Sensing, 9, 608, https://doi.org/10.3390/rs9060608, 2017.

Perez-Priego, O., El-Madany, T.S., Migliavacca, M., Kowalski, A.S., Jung, M., Carrara, A., Kolle, O., Martín, M.P., Pacheco-Labrador, J., Moreno, G., and Reichstein, M.: Evaluation of eddy covariance latent heat fluxes with independent lysimeter and sapflow estimates in a Mediterranean savannah ecosystem, Agricultural and Forest Meteorology, 236, 87-99. https://doi.org/10.1016/j.agrformet.2017.01.009, 2017.

Perez-Priego, O., Katul, G., Reichstein, M., El-Madany, T.S., Ahrens, B., Carrara, A., Scanlon, T.M., and Migliavacca, M.: Partitioning eddy covariance water flux components using physiological and micrometeorological approaches, Journal of Geophysical Research: Biogeosciences, 2018.

Pianosi, F., Iwema, J., Rosolem, R., and Wagener, T.: A Multimethod Global Sensitivity Analysis Approach to Support the Calibration and Evaluation of Land Surface Models, Sensitivity Analysis In Earth Observation Modelling, Elsevier, 125-144, 2017.

805 Raupach, M.R.: Simplified expressions for vegetation roughness length and zero-plane displacement as functions of canopy height and area index, Boundary-Layer Meteorology, 71, 211-216, 1994. 
https://doi.org/10.5194/hess-2019-354

Preprint. Discussion started: 29 August 2019

(c) Author(s) 2019. CC BY 4.0 License.

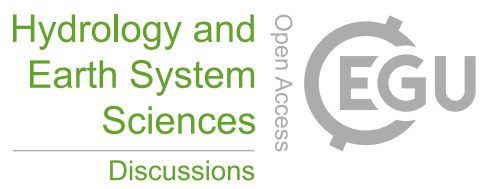

Richardson, A.D., Keenan, T.F., Migliavacca, M., Ryu, Y., Sonnentag, O., and Toomey, M.: Climate change, phenology, and phenological control of vegetation feedbacks to the climate system, Agricultural and Forest Meteorology, 169, 156-173, https://doi.org/10.1016/j.agrformet.2012.09.012, 2013.

Rosolem R., Gupta H. V., Shuttleworth W. J., Zeng X., and Gonçalves L. G. G.: A fully multiple-criteria implementation of the Sobol' method for parameter sensitivity analysis., Journal of Geophysical Research: Atmospheres, 117, https://doi.org/10.1029/2011JD016355, 2012.

Saltelli, A., Annoni, P., Azzini, I., Campolongo, F., Ratto, M., and Tarantola, S.: Variance based sensitivity analysis of model output. Design and estimator for the total sensitivity index, Computer Physics Communications, 181, 259270. https://doi.org/10.1016/j.cpc.2009.09.018, 2010.

Santanello, J.A., and Friedl, M.A.: Diurnal Covariation in Soil Heat Flux and Net Radiation. Journal of Applied Meteorology 42, 851-862, https://doi.org/10.1175/1520-0450(2003)042<0851:DCISHF>2.0.CO;2, 2003.

Sauer, T.J., and Norman, J.M.: Simulated canopy microclimate using estimated below-canopy soil surface transfer coefficients, Agricultural and forest meteorology, 75, 135-160, 1995.

Sauer, T.J., Norman, J.M., Tanner, C.B., and Wilson, T.B.: Measurement of heat and vapor transfer coefficients at the soil surface beneath a maize canopy using source plates, Agricultural and Forest Meteorology, 75, 161-189, 1995.

Schaudt, K.J., and Dickinson, R.E.: An approach to deriving roughness length and zero-plane displacement height from satellite data, prototyped with BOREAS data. Agricultural and Forest Meteorology, 104, 143-155, 2000.

Sobol', I.M.: Global sensitivity indices for nonlinear mathematical models and their Monte Carlo estimates, Mathematics and Computers in Simulation, 55, 271-280, https://doi.org/10.1016/S0378-4754(00)00270-6, 2001.

Sobrino, J.A., Jiménez-Muñoz, J.C., Verhoef, W: Canopy directional emissivity: Comparison between models, Remote Sens. Environ., 99, 304-314, https://doi.org/10.1016/j.rse.2005.09.005, 2005

Song, X., Zhang, J., Zhan, C., Xuan, Y., Ye, M., and Xu, C.: Global sensitivity analysis in hydrological modeling: Review of concepts, methods, theoretical framework, and applications, Journal of Hydrology, 523, 739-757, https://doi.org/10.1016/j.jhydrol.2015.02.013, 2015.

Stoy, P.C., El-Madany, T., Fisher, J.B., Gentine, P., Gerken, T., Good, S.P., Liu, S., Miralles, D.G., Perez-Priego, O., Skaggs, T.H., Wohlfahrt, G., Anderson, R. G., Jung, M., Maes, W. H., Mammarella, I., Mauder, M., Migliavacca, M., Nelson, J. A., Poyatos, R., Reichstein, M., Scott, R. L., and Wolf, S. : Reviews and syntheses: Turning the challenges of partitioning ecosystem evaporation and transpiration into opportunities. Biogeosciences Discuss., https://doi.org/10.5194/bg-2019-85, in review, 2019.

Su, Z.: The Surface Energy Balance System (SEBS) for estimation of turbulent heat fluxes, Hydrol. Earth Syst. Sc., 6(1),

85-100, 2002.

Timmermans, W.J., Kustas, W.P., Anderson, M.C., and French, A.N.: An intercomparison of the Surface Energy Balance Algorithm for Land (SEBAL) and the Two-Source Energy Balance (TSEB) modeling schemes, Remote Sens. Environ., 108, 369-384, https://doi.org/10.1016/j.rse.2006.11.028, 2007.

van Griensven, A., Meixner, T., Grunwald, S., Bishop, T., Diluzio, M., and Srinivasan, R.: A global sensitivity analysis tool for the parameters of multi-variable catchment models, Journal of Hydrology, 324, 10-23. https://doi.org/10.1016/j.jhydrol.2005.09.008, 2006.

Weligepolage, K., Gieske, A.S.M., van der Tol, C., Timmermans, J., and Su, Z.: Effect of sub-layer corrections on the roughness parameterization of a Douglas fir forest, Agricultural and forest meteorology, 162, 115-126, 2012.

Xu, T., Bateni, S.M., Margulis, S.A., Song, L., Liu, S., and Xu, Z.: Partitioning Evapotranspiration into Soil Evaporation and Canopy Transpiration via a Two-Source Variational Data Assimilation System, J. Hydrometeorol., 17, 2353-2370, https://doi.org/10.1175/JHM-D-15-0178.1, 2016.

Zhang, X., Trame, M., Lesko, L., and Schmidt, S.: Sobol Sensitivity Analysis: A Tool to Guide the Development and Evaluation of Systems Pharmacology Models, CPT: pharmacometrics \& systems pharmacology, 4, 69-79. https://doi.org/10.1002/psp4.6, 2015. 
https://doi.org/10.5194/hess-2019-354

Preprint. Discussion started: 29 August 2019

(c) Author(s) 2019. CC BY 4.0 License.

\section{Appendix A}

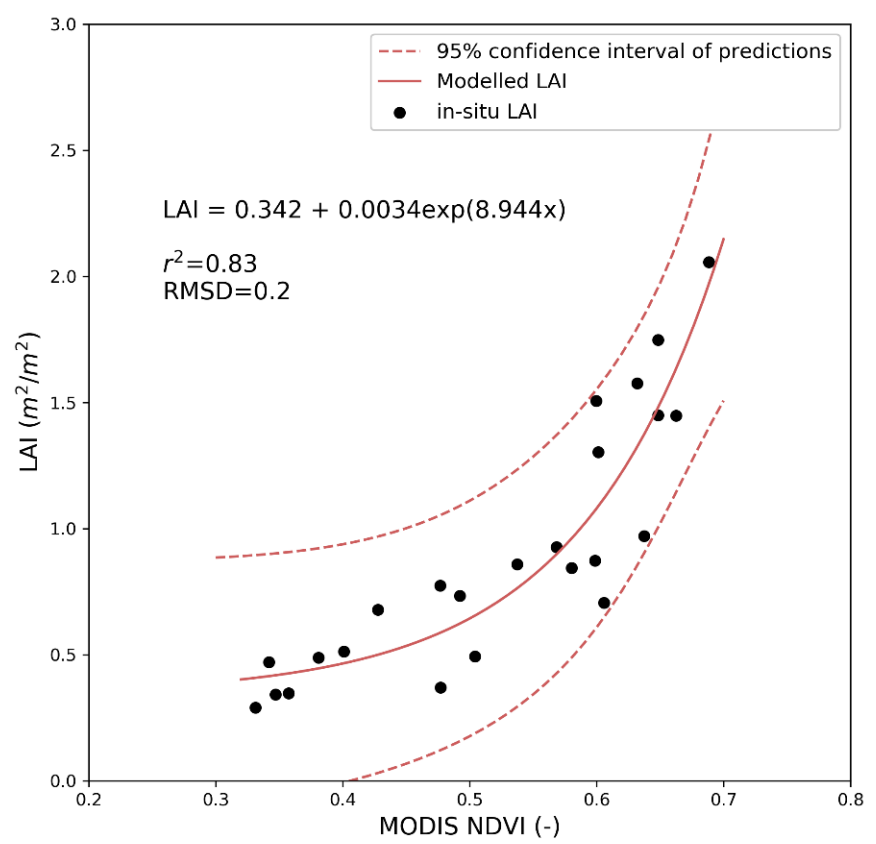

Figure A1. Empirical model between MODIS (MCD43A4) NDVI and in-situ destructive grass LAI measurements developed for Majadas experimental site.

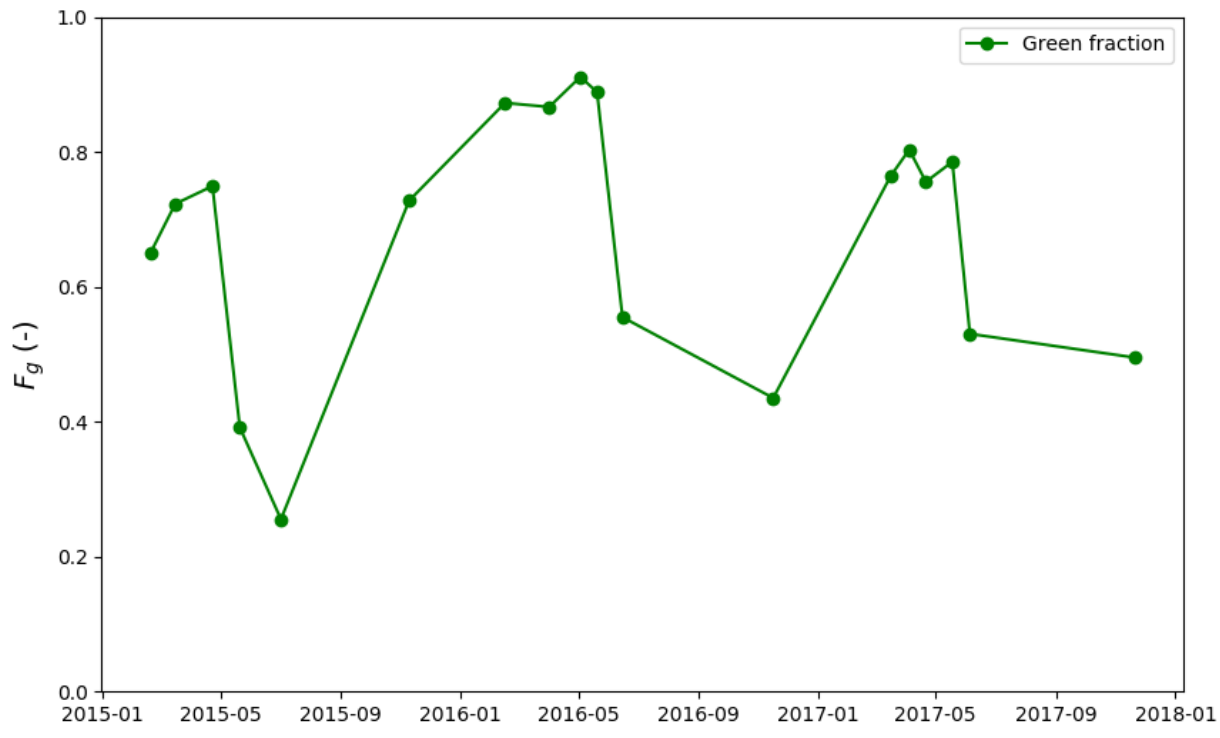

860 Figure A2. Field measurements of green fraction $\left(f_{g}\right)$ from gravitational methods (section 2.3.2) 
https://doi.org/10.5194/hess-2019-354

Hydrology and

Preprint. Discussion started: 29 August 2019

(c) Author(s) 2019. CC BY 4.0 License.
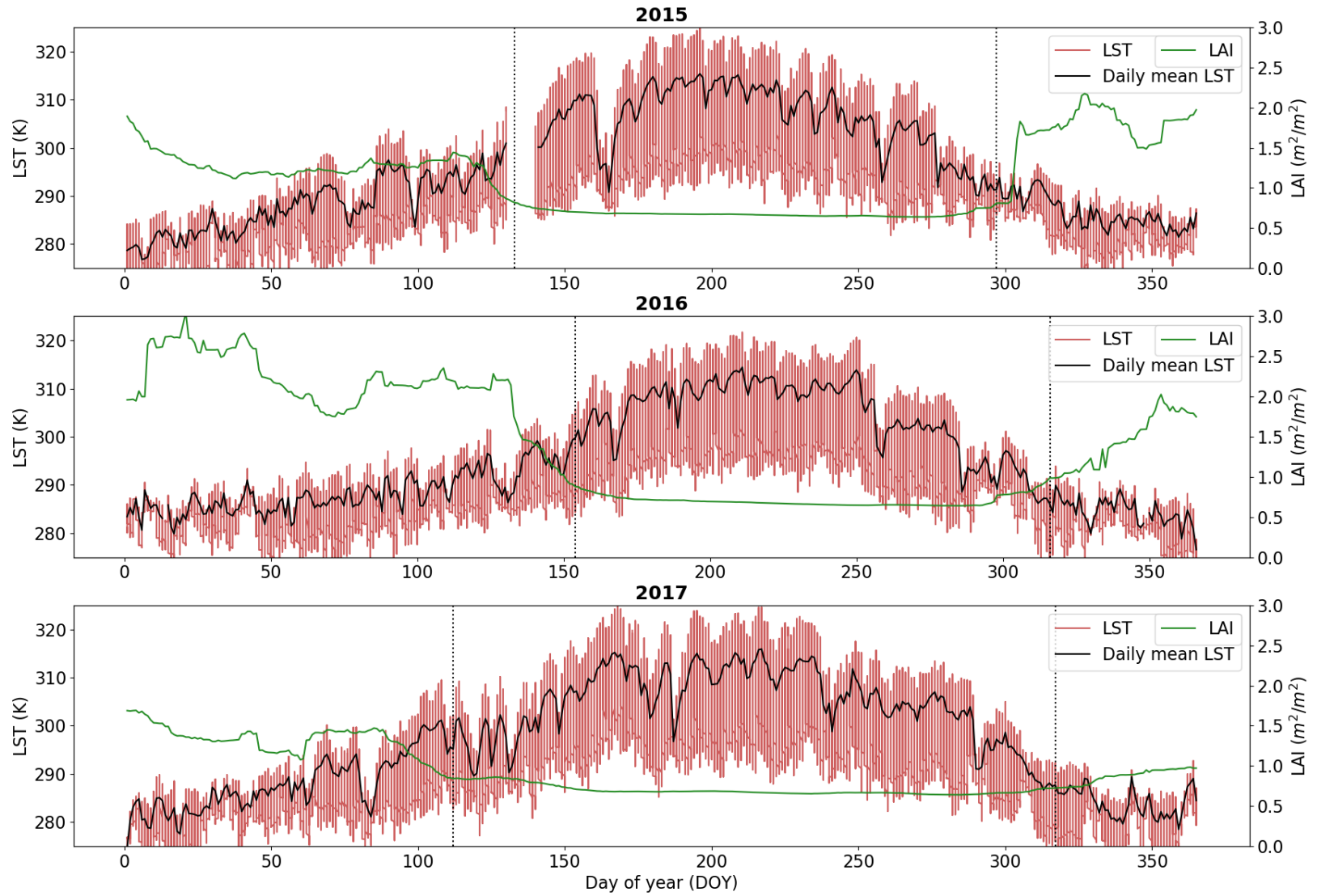

Figure A3. Annual time series of half-hourly LST (red), daily average LST (black) and daily LAI (green) for 2015,2016 and 2017 at the CT tower. Vertical dashed lines indicate transition dates used for TSEB-2S (dry periods - 2015: DOY 133-297; 2016: DOY 154-316; 